\title{
A review on the vortex tube geometrical affecting parameters
}

Mustafa ABDULHUSSAIN

DOI: $10.30464 /$ jmee.2020.4.1.69

Cite this article as:

Abdulhussain M. A review on the vortex tube geometrical affecting parameters. Journal of Mechanical and Energy Engineering, Vol. 4(44), No. 1, 2020, pp. 69-88.

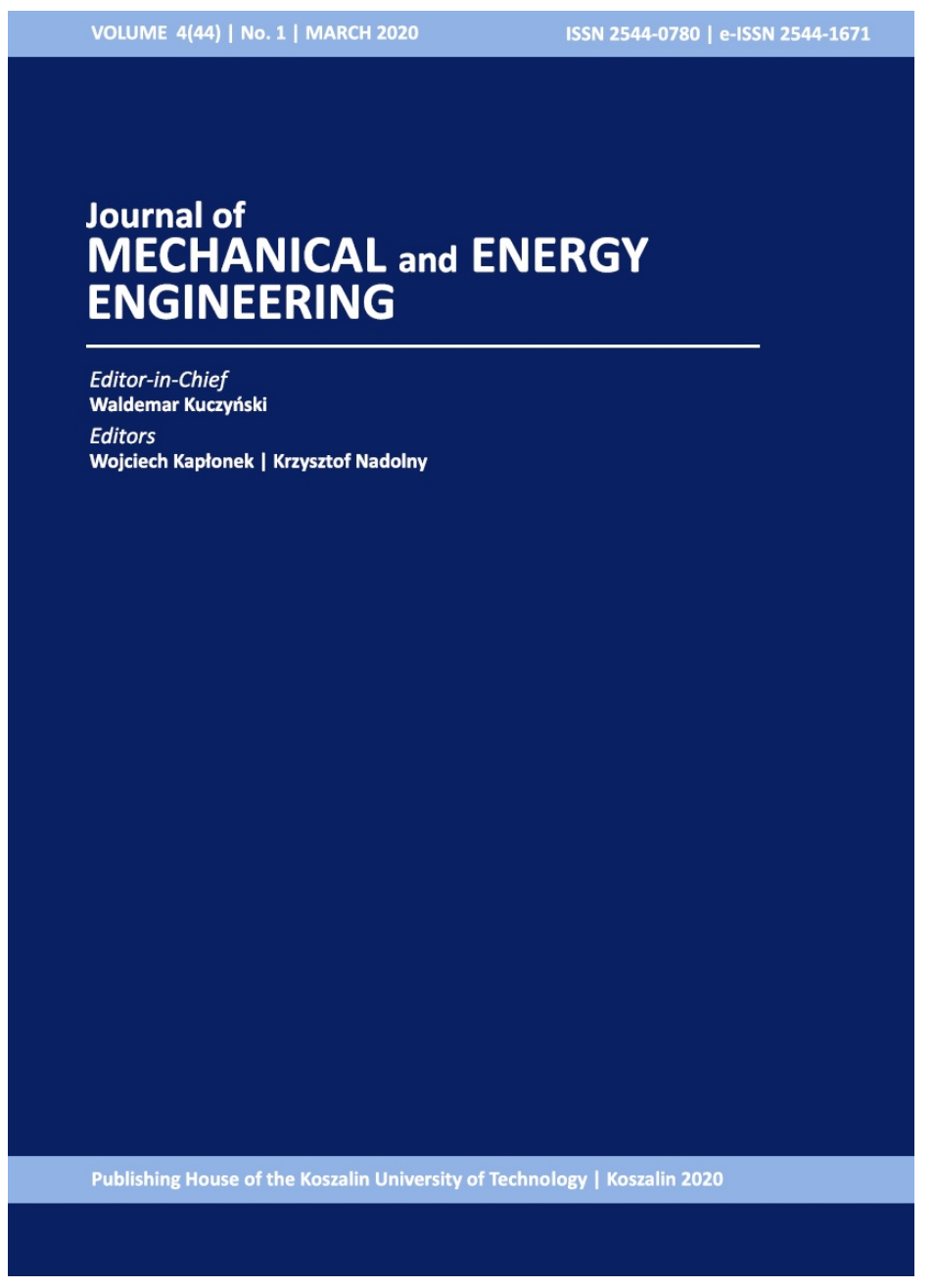

Journal of Mechanical and Energy Engineering

Website: jmee.tu.koszalin.pl

ISSN (Print): 2544-0780

ISSN (Online): 2544-1671

Volume: 4(44)

Number: 1

Year: 2020

Pages: 69-88

Article Info:

Received 2 March 2020

Accepted 6 March 2020

\section{Open Access}

This article is distributed under the terms of the Creative Commons Attribution 4.0 (CC BY 4.0) International License (http://creativecommons.org/licenses/by/4.0/), which permits unrestricted use, distribution, and reproduction in any medium, provided you give appropriate credit to the original author(s) and the source, provide a link to the Creative Commons license, and indicate if changes were made. 


\title{
A REVIEW ON THE VORTEX TUBE GEOMETRICAL AFFECTING PARAMETERS
}

\author{
Mustafa ABDULHUSSAIN ${ }^{1 *}$ \\ ${ }^{1 *}$ Department of Mechanical Engineering, University of Technology, Baghdad, Iraq, \\ e-mail: mustafa_ahmed2018@yahoo.com
}

(Received 2 March 2020, Accepted 6 March 2020)

\begin{abstract}
One of the increased usability energy separation devices that deals with compressed fluids such as the air, the water, and several Refrigerants are the Ranque-Hilsch vortex tube due to its simple operating principle to separate the compressed fluid to two hot and cold streams. The aim of the current paper is to review the Ranque-Hilsch tube flow separation most affecting geometrical parameters influencing the thermal separation efficiency in the literature that are conducted numerically and experimentally such as the number of injection nozzles and their cross-sectional shape including the rectangular and the trapezoidal for straight constant and converged nozzle profiles as well as the helical swept nozzle configurations like the nozzles aspect and the convergence ratios, the variation of the helical profile pitch angle with the increase in the nozzles number is also considered in the survey, further geometrical parameters survey is performed that includes the vortex tube orifice size to the nozzle's length dimensional ratio and also the vortex tube configuration like the divergent and the convergent/divergent vortex tube shapes characteristics that includes the divergent angle and the throttling zone size in addition to the vortex tube length to the hot exit port size ratio and the optimum conical valve shape position and tapering angle.
\end{abstract}

Keywords: Ranque-Hilsch review, vortex tube configuration, injection nozzle

\section{INTRODUCTION}

The highest durability vortex generation tool in addition to the efficient thermodynamic fluid separation process [1] is the Ranque-Hilsch vortex tube (Figure 1) when the highly pressurized fluid enters the vortex generation mixing chamber through the circumferential nozzles via the inlet tubes ports and then circulates normally to be flown axially inside the vortex tube body until reaching the votes tube conical exit valve that illuminates the discharge exit area, here the circulated fluid flow will be affected by the contraction zone and will be separated into two flow regimes hot and cold; the cold fluid that has less internal energy will be swept back reversely into the cold exit port while the hot flow stream will continue its way via the conical valve exit port. The complexity of the energy flow separation phenomena inside the RHVT and its hard-physical explanation has led to intensive research efforts throughout the decades to improve the device separation efficiency and its application expansion for the refrigeration and the heat exchange devices. These research efforts are categorized within the main following directions.

1. The operating fluid category and its phase condition regarding the most optimum thermal conditions for a specific RHVT type.

2. The separation efficiency of the RHVT in the heat exchange devices with or without phase change.

3. The study of the RHVT geometry changing parameters that affect the energy separation process that includes the device operation for different fluid categories, conditions, and applications.

In this review, the focus will be to survey the numerical and experimental researches that handled the latest RHVT efficiency affecting parameters concerning its geometry specifications that include the VT inlet nozzles configuration, the VT nozzles to the orifice dimensional ratio and also the VT shape configuration plus the conical valve cone angle effect. 


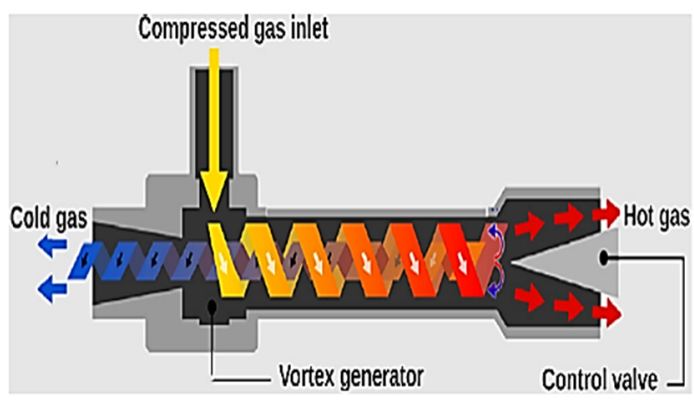

Fig. 1. The Ranque-Hilsch vortex tube [1]

\section{REVIEWING THE RANQUE-HILSCH VORTEX TUBE SOURCES}

\subsection{The nozzles configuration}

The effect of various nozzle inlet port configurations, including rectangular and trapezoidal uniform cross-sectional shape (as a single inlet nozzle) on the energy separation for constant pressure compressed air passing through an insulated type RHVT is performed numerically by R. Manimaran (2016) [2] using the ANSYS FLUENT with the variation of the cross-section aspect ratio from (0.75-3.0), respectively. From the experimental tests, the maximum cold air fraction does not exceed (40\%) of the total airflow and assuming the thermal conductivity of air is constant, the adoption of the Reynolds stress turbulence model in the numerical solution is performed and the VT cross-sections dimensions are varied (Figure 2) in order to maintain a constant cross-sectional area so as to maintain a stable mass flow rate. The results showed that the increase of the aspect ratio for the trapezoidal cross-section gives the higher temperature separation process with increased hot streamlines towards the conical valve exit other than the rectangular section.

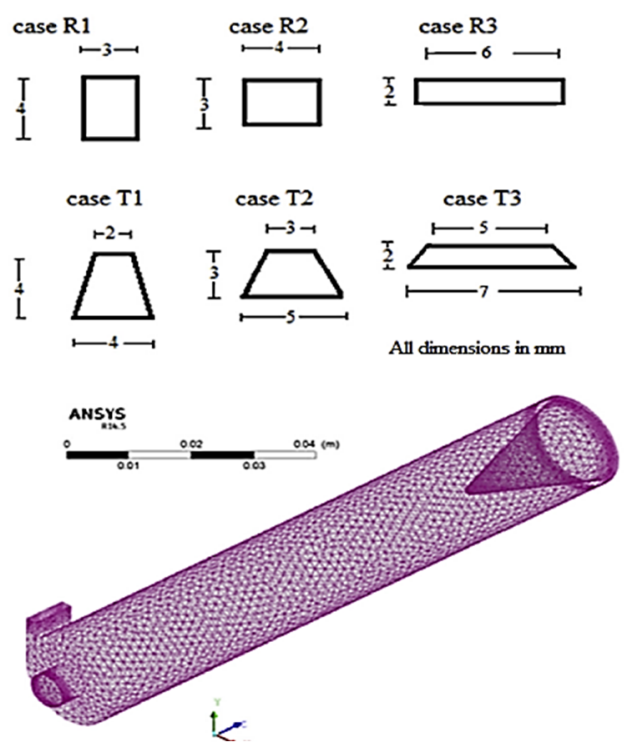

Fig. 2. The nozzles adapted configuration [2]
These results are validated with the experimental testing of the rectangular cross-section VT case R1 profile and showed that the percentage error in the cold flow, temperature difference change with respect to the increase in the cold flow mass fraction does not exceed $1 \%$ (Figure 3).

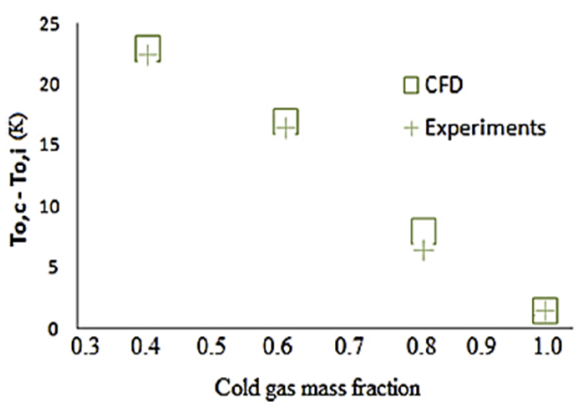

Fig. 3. The numerical results validation [2]

More nozzle cross-sectional shapes with constant dimensions such as the circular, the elliptical and the hexagonal contours as well as the pre-mentioned figures by R. Manimaran (2016) [2] are investigated numerically by F. Fidus, R. Mathew, A. Nidhan, S. Mohan and J. Chandran (2017) [3], the researchers study concentrated on the VT mean temperature difference variation, the inlet rectangular cross-section with a constant area gives the best energy separation efficiency while the circular has achieved the lowest efficiency.

The utilization of straight and constant curved axial helical nozzles in the RHVT is investigated numerically by P. Kaushal, S. Bux, and A. Paul (2016) [4] using ANSYS FLUENT using the standard $K-\varepsilon$ turbulence model. The number of straight flow injection nozzles to the mixing chamber is varied from (3-6) while their number is set to (3) when utilizing the helical nozzles, the velocity field contours for the straight nozzles shows a local increase in the flow momentum at the mixing chamber entrance region followed by a gradual decrease in its value that is slightly increased as the number of inlet nozzles ports are increased. The results for the helically shaped inlet configuration nozzles showed a semi-uniform flow momentum in the mixing chamber zone that is decreased slightly when enters the VT body where it produces a higher swirling flow and temperature difference for the two fluid streams (Figures 4-6).

Four types of nozzles profiles have been utilized in the CFD simulation of the RHVT by N. Kumar and A. S. Malipatil (2014) [5] using the realizable $K-\varepsilon$ turbulence modeling. The simulation is performed with two kinds of nozzles cross-sections (Figure 7) that are the rectangular and the circular shapes that have been swept in both linear and helical curved path, keeping the nozzle dimensions constant along with them with adopting the number of the nozzles to three. 


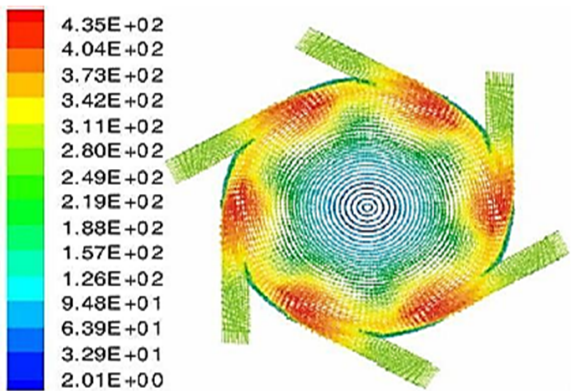

Fig. 4. The swirling velocity profile for (6) straight nozzles [4]

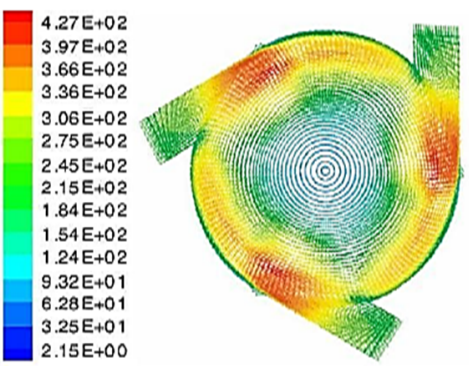

Fig. 5. The swirling velocity profile for (3) straight nozzles [4]

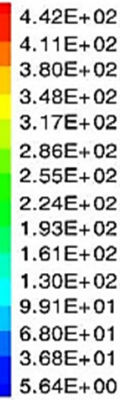

Fig. 6. The swirling velocity profile for (3) helical nozzle [4]
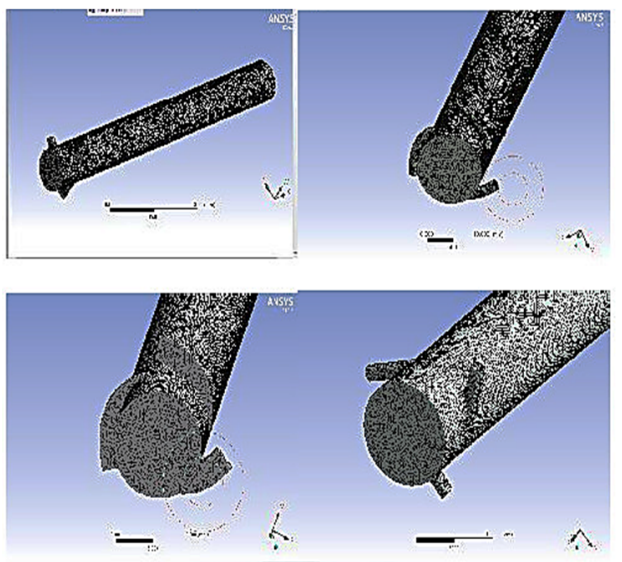

Fig. 7. The utilized nozzles configurations [5]
Considering that the energy separated flow is compressed air that is treated as an ideal gas in the FLUENT simulation software setting the main inlet flow to a constant mass flow rate of $(8.35 \mathrm{gm} / \mathrm{sec})$ and the two outlets separated flow to $(20$ and $15 \mathrm{kPa})$ for the hot and the cold flow, respectively. The simulation results validation with previously performed researches (Figure 8) shows that the flow total temperature variation along with the VT when utilizing the circular nozzle profile with helical path represents the best accurately predicted thermal domain behavior.

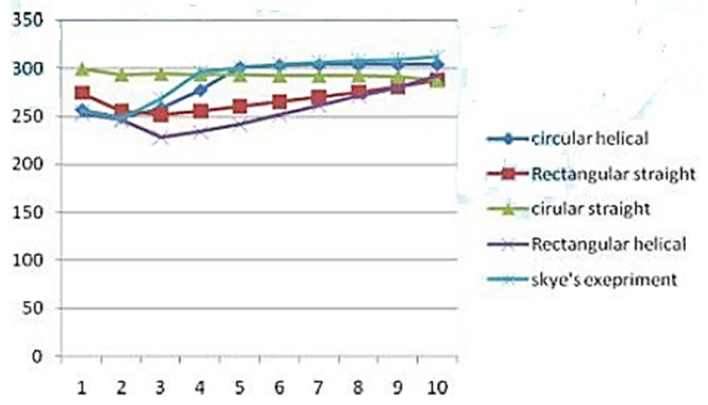

Fig. 8. The numerical validation results [5]

An overview of the velocity flow pattern of the four utilized nozzles configurations (Figures 9 a-d) shows that the helical nozzle path especially with a rectangular profile (Figure 9b) has a higher rate of locally increased flow velocity due to the increased momentum zones within the nozzle path.

An additional investigation on the counter flow VT models that have nozzles number ranging from (2-6) with the variation of the flow inlet pressure from (200-600 kPa) in addition to the cold mass fraction from (0.4-0.9), respectively is performed experimentally by H. Ahmed, M. S. Ahmed, M. Attalla, and A. A. El-Wafa (2017) [6]. The straight path nozzles with constant aspect ratio and inner diameter are adopted in the experiment's tests (Figure 10) in order to monitor the cold flow mass fraction change.

The results show that the cold flow temperature drop becomes higher as the flow inlet pressure is increased (Figure 11) but this rate becomes lower when the cold flow mass fraction is decreased since it will produce flow chocking near the VT hot exit port.

When the number of the nozzles is raised to (6), a deeper drop in the cold flow temperature difference is produced (Figure 12) especially for a cold flow mass fraction exceeds (0.65).

For rectangular shape straight flow nozzle, the optimum dimensions, including the cross-section width and height are investigated computationally by A. Bazgir and A. Heyderi (2018) [7] (Figure 13) using the $K-\mathcal{E}$, the $K-\omega$, and the SST turbulence models. 
a)

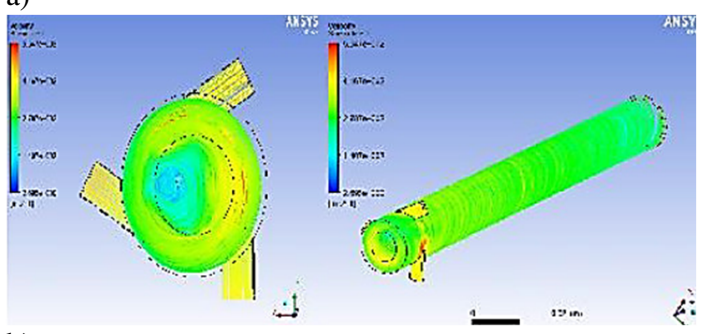

b)

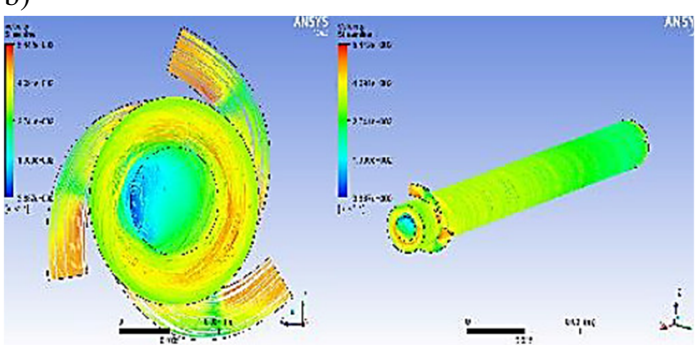

c)

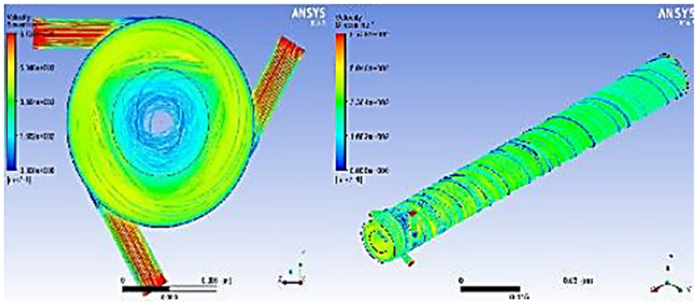

d)

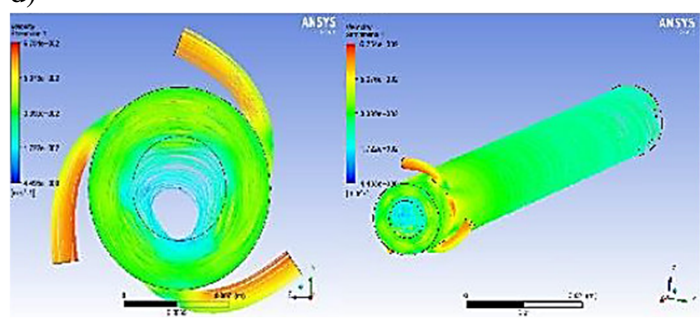

Fig. 9. The flow velocity streamlines for the selected nozzles: a) The straight rectangular, b) The helical rectangular, c) The straight circular, d) The helical circular [5]

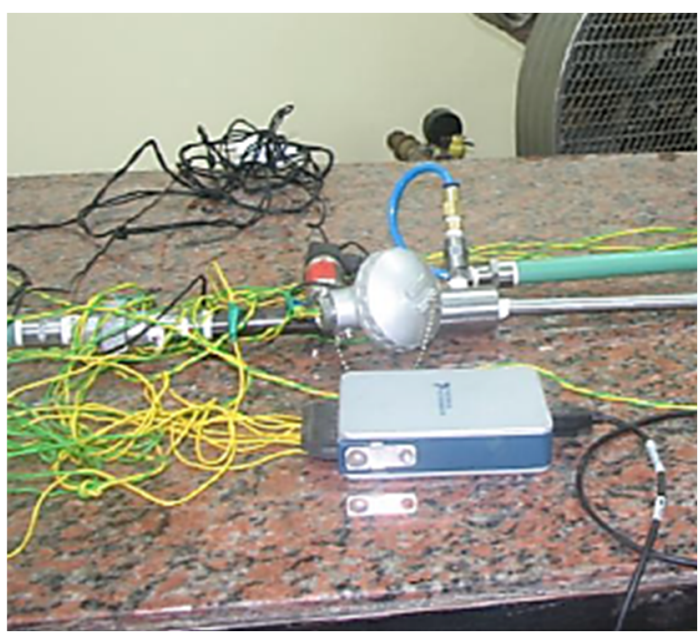

Fig. 10. The adopted VT test rig [6]

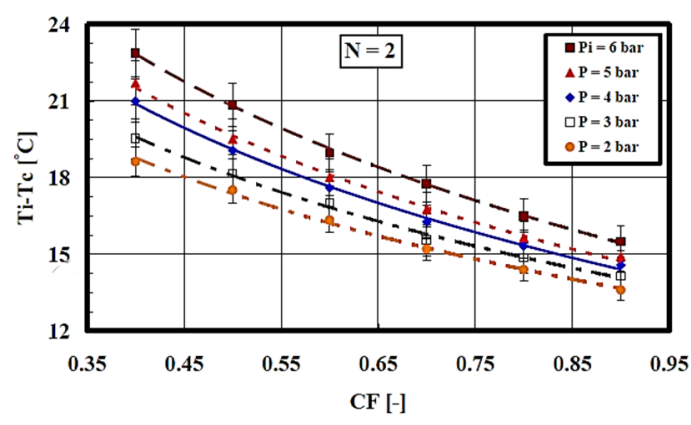

Fig. 11. The cold flow temperature drop with its mass fraction change [6]

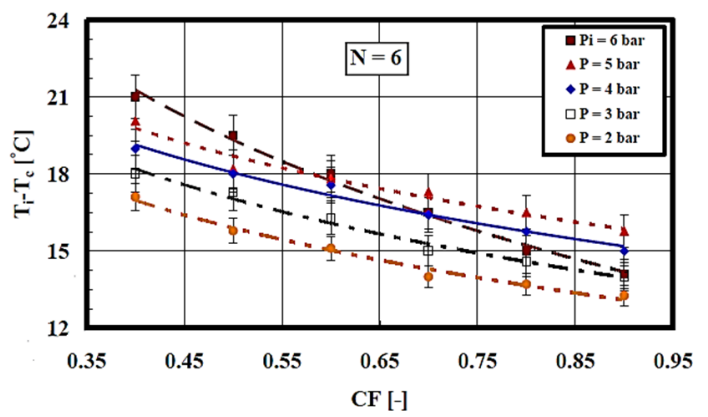

Fig. 12. The cold flow temperature drop with its mass fraction change [6]

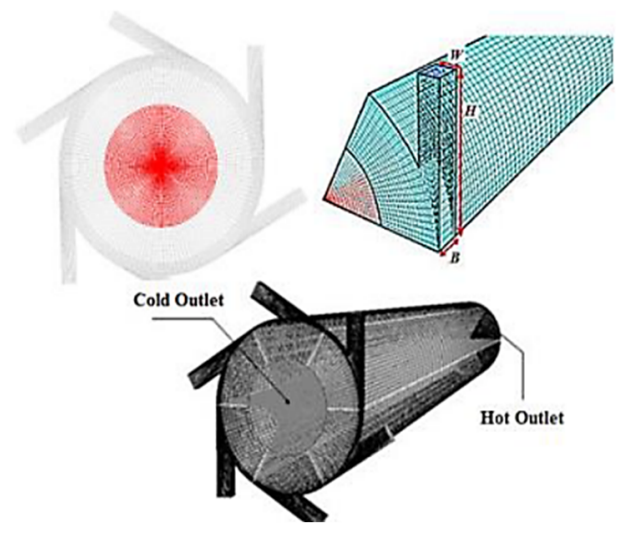

Fig. 13. The definition of the VT nozzle dimensions [7]

For constant dimensions and inlet flow conditions to the VT, the nozzle height effect is small in spite of the nozzle width that produces more temperature drop for cold flow. The results validation with experimental survey studies showed that the $K-\varepsilon$ model achieved the best accuracy results for the cold gas temperature variation with its mass fraction (Figure 14).

The utilization of the helical nozzle with a variable pitch angle is studied numerically by Y. Oh, and K. Kim (2016)[8] to study the axial and the swirling velocity components profile variation in a constant dimension insulated RHVT where the pitch angle $(\beta)$ (Figure 15) is increased from (0-15) degrees by (5) degree step. This parameter change has increased the temperature change between the resulted hot and cold separated 
flows and it was found that the pitch angle of (5) degrees achieved the best swirling flow velocity distribution which means better vorticity generation while the highest axial flow velocity profile along the vortex tube for the hot and cold streamlines is appointed when the pitch angle equals $(15 \& 5)$ degrees as denoted in (Table 1)

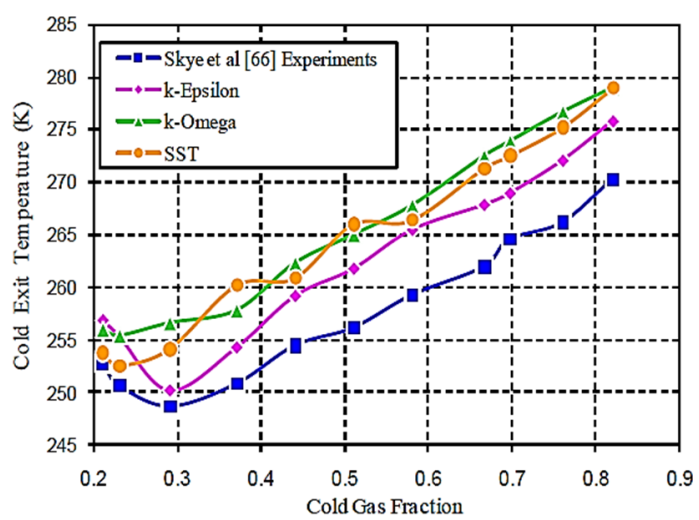

Fig. 14. The numerical results validation [7]

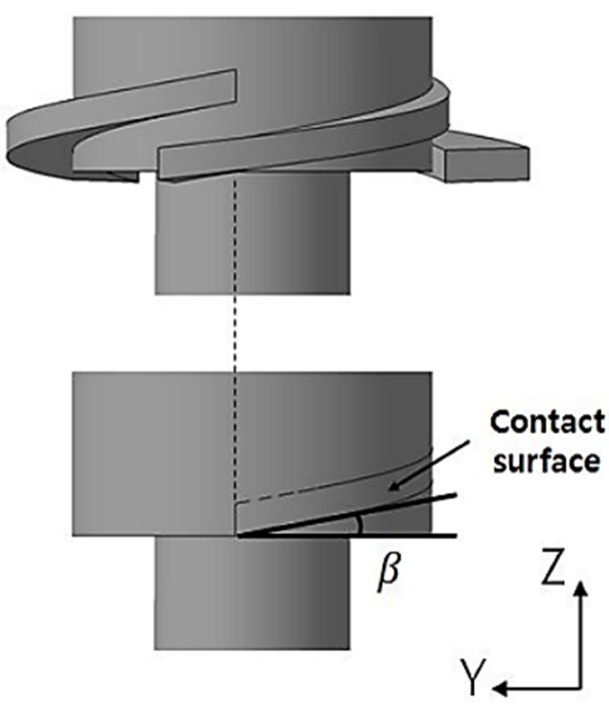

Fig. 15. The helical nozzle with the defined pitch angle [8]

The convergent path linear nozzles with gradual area decreased utilization in the RHVT with a variable number of inlet ports and increased contraction rate for the nozzle cross-section is performed numerically using The FLUENT package and validated experimentally by M. Sadeghiazad (2017) [9]. The numerical solution is performed using the standard $K-\varepsilon$ and the RNG turbulence model as well as the Reynolds stress model, the cross-section contraction rate is defined by the nozzle inlet port width divided by the nozzle entrance width of the mixing chamber defined by symbols $s I$ and $s_{2}$ (Figure 16), respectively.
Tab. 1. The separated flow velocity variation with pitch angle [8]

\begin{tabular}{lcccc}
\hline \multirow{2}{*}{ Parameter } & \multicolumn{4}{c}{ Pitch Angle } \\
\cline { 2 - 5 } & 0 & 5 & 10 & 15 \\
\hline $\begin{array}{l}\text { Swirl Velocity } \\
{[\mathrm{m} / \mathrm{s}]}\end{array}$ & 105.66 & 105.71 & 103.46 & 103.80 \\
\hline $\begin{array}{l}\text { Axial Velocity } \\
\text { (hot flow) [m/s] }\end{array}$ & 13.35 & 12.54 & 14.25 & 16.86 \\
\hline $\begin{array}{l}\text { Axial Velocity } \\
\text { (cold flow) }[\mathrm{m} / \mathrm{s}]\end{array}$ & 56.52 & 58.21 & 57.28 & 55.63 \\
\hline
\end{tabular}

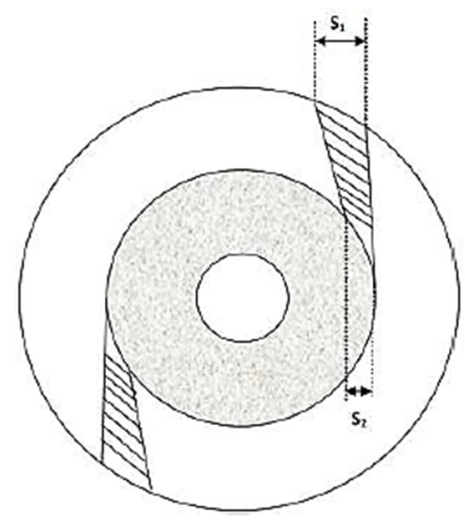

Fig. 16. The utilized straight convergent nozzle [9]

In order to achieve the highest conservation target from the numerical solution of the governing equations, a mesh dependency test is performed by the author to detect the cold mass flow temperature difference in terms of the minimum flow control volume cell volume. The change in the desired quantity (Figure 17) shows the best mesh refining occurs between $\left(0.03-0.08 \mathrm{~mm}^{3}\right)$.

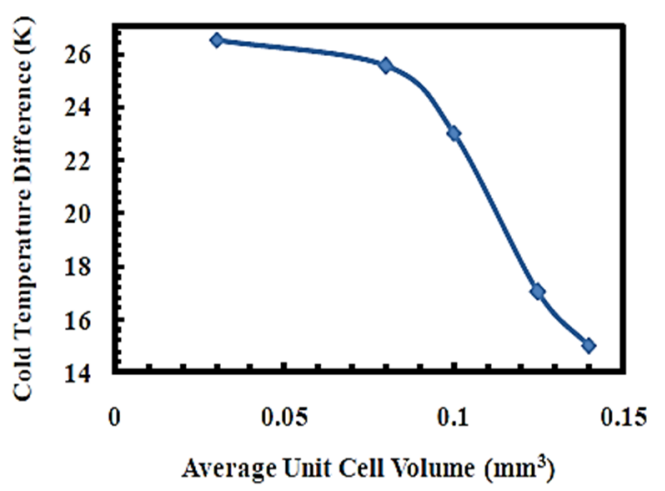

Fig. 17. The mesh dependency testing [9]

The results indicated that within the nozzle contraction ratio between (1-2.85), the best value of the cold flow temperature drop is achieved at (1.9) nozzle contraction, the nozzles inlet ports increase has a great influence on the cold flow temperature drop especially when the cold flow volume fraction is lower to the entire domain (Figure 18). 


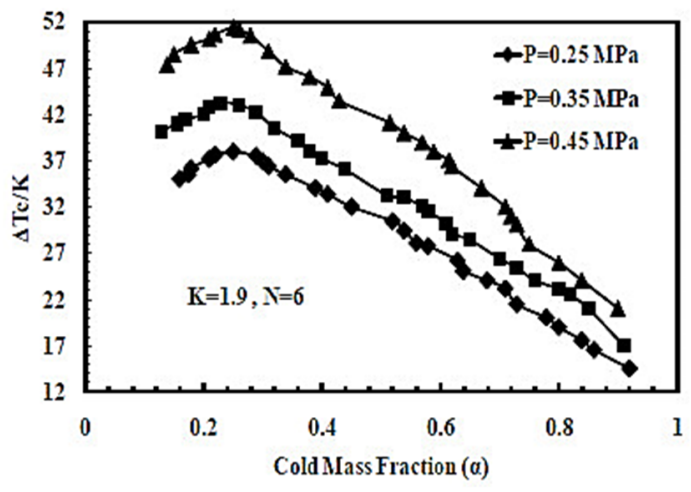

Fig. 18. The temperature variation with respect to pressure drop and the cold mass fraction ratio [9]

A newly adopted modification in the nozzles injection ports is tested experimentally by S. Rafiee and M. Sadeghiazad (2020) [10] via the incorporation of a $\mathrm{V}$-shape grooved flow navigator at the entrance region of the VT mixing chamber (Figure 19).
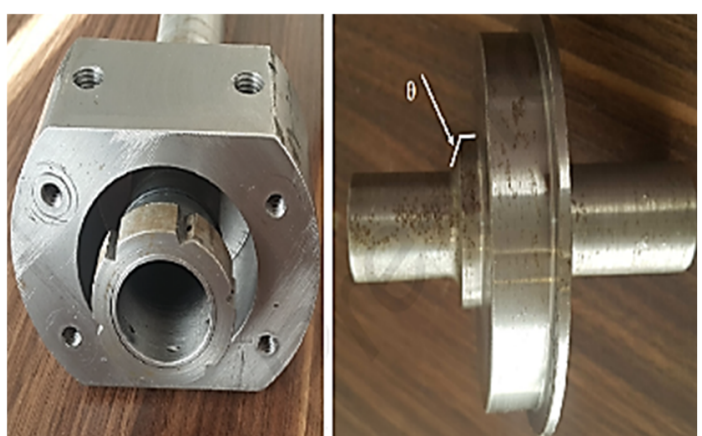

Fig. 19. The utilizing of grooved navigator in the VT [10]

With the variation of the grooving angle from (0-15 degrees), the separated flow swirling and axial velocity components response is observed in addition to the hot and cold flow temperature difference.

The maximum temperature difference in the cold flow is detected when the navigator angle is about $\left(10^{\circ}\right)$ for low values of the mass fraction $(>0.4)$, then this parameter change becomes insignificant as the cold flow portion is raised (Figure 20).

The researchers performed the numerical solution for the problem assuming the compressible turbulent flow of air which is treated as an ideal gas and adopting the RNG K- $\varepsilon$ turbulence model defining the tube centerline as an axis of symmetry and the required grid distribution for the validation of the results is selected among various meshing sizes (Figure 22) where the researchers considered the (600000) nodes as an adequate for the solution.

A simple but active modification to the RHVT by converting its sharp circumferential edge to a half-circular profile around the mixing chamber edge (Figure 21) is made by R. Shamsoddini, and B. Abolpour (2018) [11] which can serve as an economical manufacturing purpose through the reducing of the utilized number of injection nozzles.

As a comparison, the effect of converting the mixing chamber edge with the same utilized nozzles number of (2) shows a deeper cooling effect near the central location of the VT (Figure 23) while the flow temperatures close to the VT wall remain unchangeable, this behavior will compensate for further increment in the utilized nozzles.

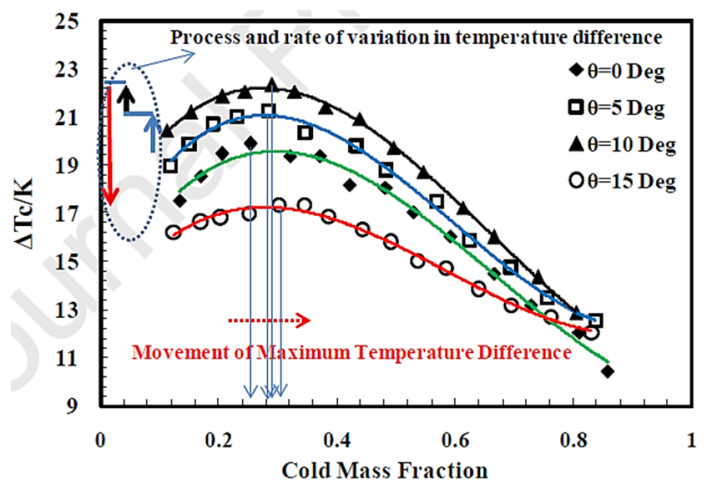

Fig. 20. The cold flow temperature change with navigator angle [10]
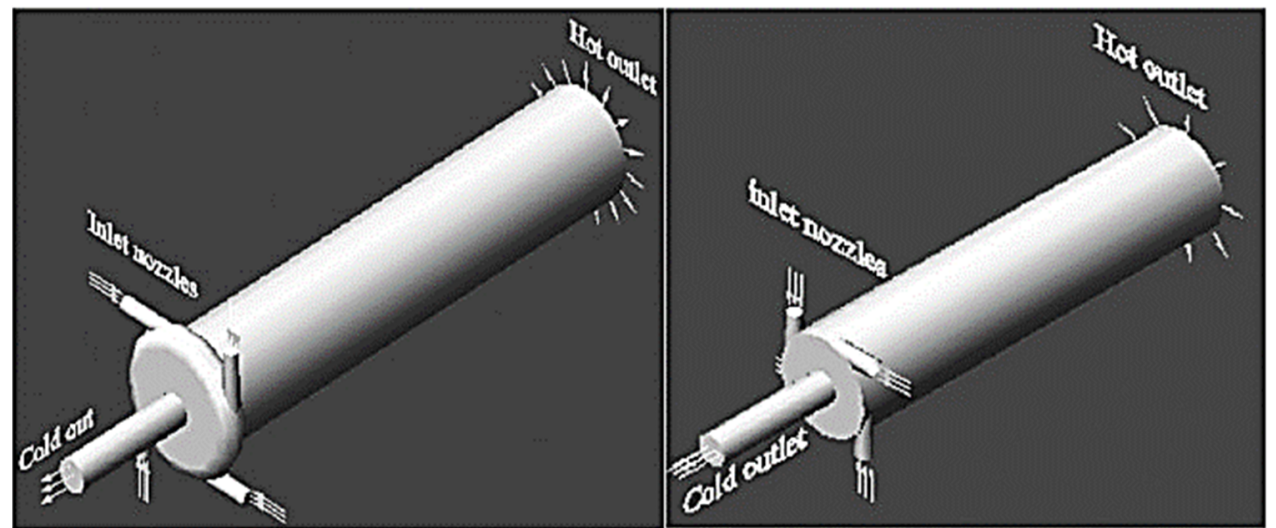

Fig. 21. The RHVT chamber modification [11] 


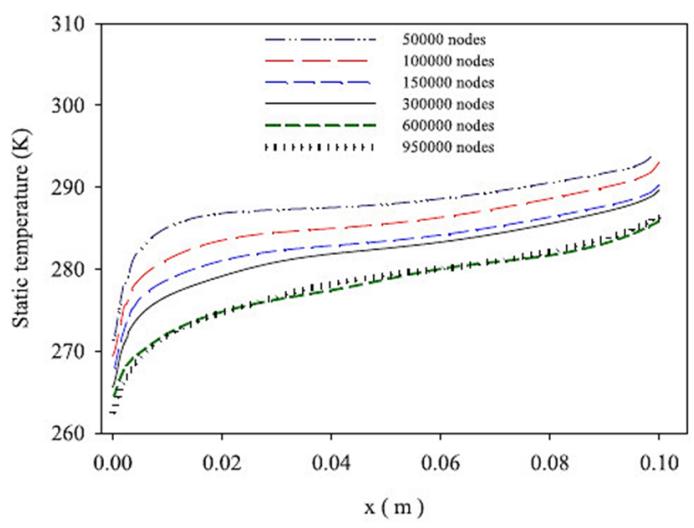

Fig. 22. The grid dependency results [11]

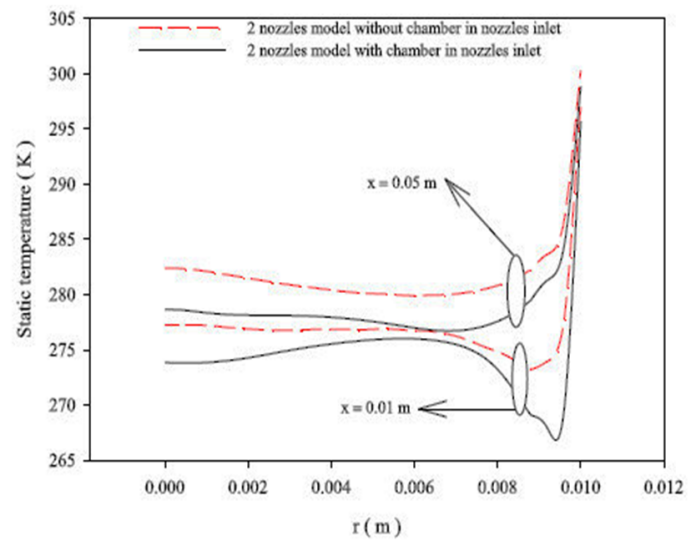

Fig. 23. The mixing chamber conversion effect [11]

\subsection{The nozzles to the vortex tube orifice} dimensional ratio

When the cold flow is generated in the VT and passing in the reverse flow direction, it passes through a cylindrical orifice in the Ranque Hilsch tube, an investigation of the orifice to the VT diameter ratio effect on the coefficient of performance when utilizing the RHVT inside a closed-loop Refrigeration system is carried out by S. Abdelghany and H. Kandil (2018) [12] numerically for different cold flow mass fraction rates using the $K-\varepsilon$ turbulence model and applying the middle flow center line in the VT as an axis of symmetry for the entire domain (Figure 25).

The results showed that the RHVT COP is positively varied as the orifice to the tube diameter ratio is increased when the cold flow mass fraction remains constant noticing that the optimum range for the cold mass fraction is between (0.6-0.7) that gives the best RHVT COP (Figure 24).

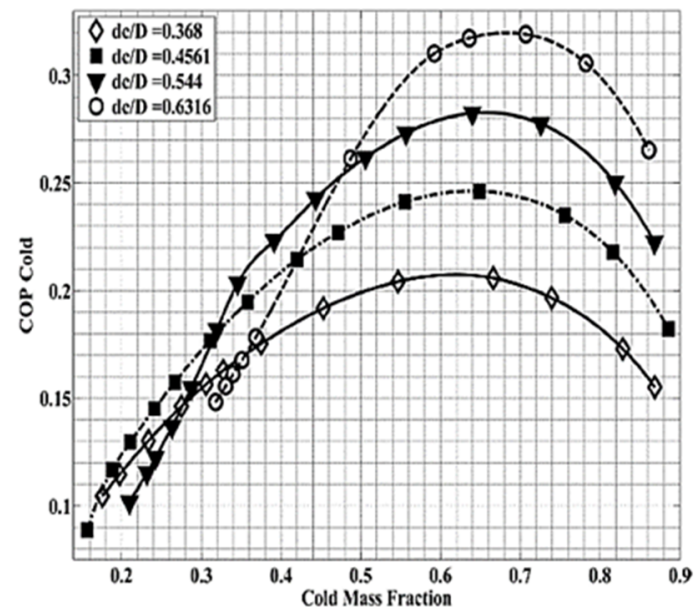

Fig. 24. The orifice to tube diameter ratio on VT COP [12]

The synchronization between the tube length and the cold orifice size to achieve the best rate of optimizing the VT having two entering nozzles is investigated numerically by M. Suhaimi and M. Yusof (2018) [13] using the SIMFLOW software for a fixed hot and cold outlet conditions (Figure 26). Seven different gases that are Air, Ammonia, Carbon Dioxide $\&$ Monoxide, Helium, Methane, and Nitrogen are adopted in the simulation process with constant inlet properties.

The results showed that the best VT performance reached its maximum rate in temperature difference when the helium gas is utilized remarking that the best VT optimization is detected when the tube length and orifice size reaches (175) and (4) millimeters (Figure 27), respectively.

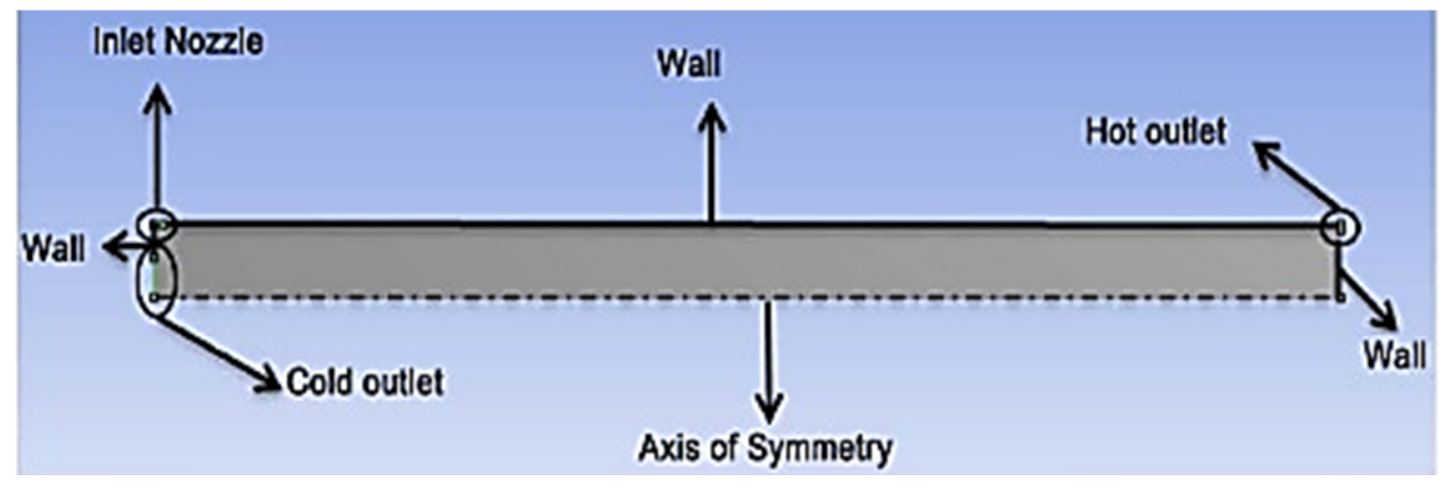

Fig. 25. The simulation applied boundary conditions [12] 
The effect of the increased orifice diameter that ranges from (2-6) millimeters (Figure 28) on the hot/cold flow temperature difference in addition to the isentropic efficiency for the RHVT is conducted experimentally by Kh. Abd Rahman, W. Valliyappan, D. Natarajan, and Y. Istihat (2017) [14] with the variation of air inlet pressure. The optimum orifice size of (4) $\mathrm{mm}$ at an inlet flow pressure of (15) bar achieved the highest value efficiency as in Fig. 29a and noticing the flow increased pressure produces more flow temperature difference. In addition, the orifice increased size from $(2-6 \mathrm{~mm})$ with constant inlet pressure has a positive gain on the hot flow mass fraction as shown in Fig. 29b.

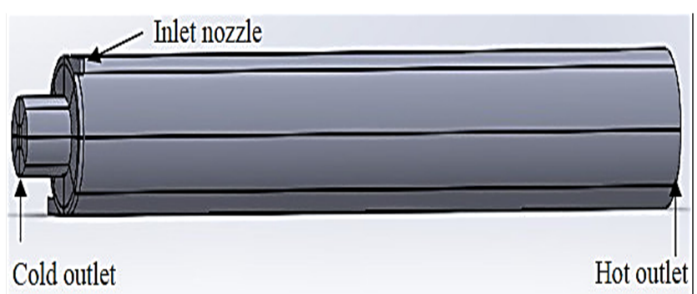

Fig. 26. The two nozzles configured VT [13]

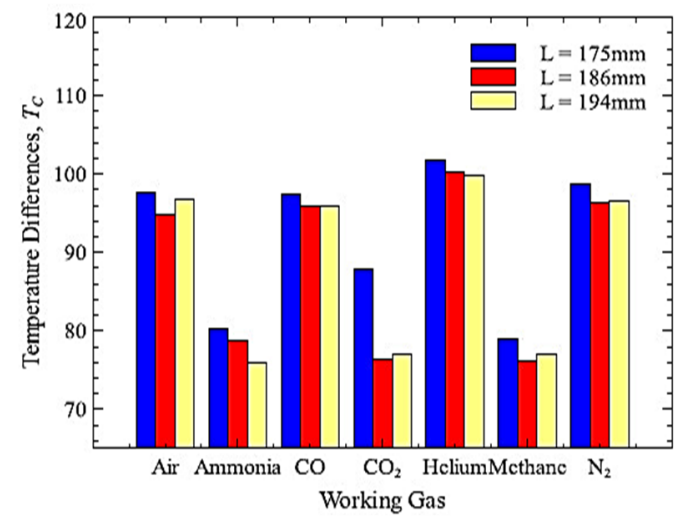

Fig. 27. The utilized gases performance comparison [13]

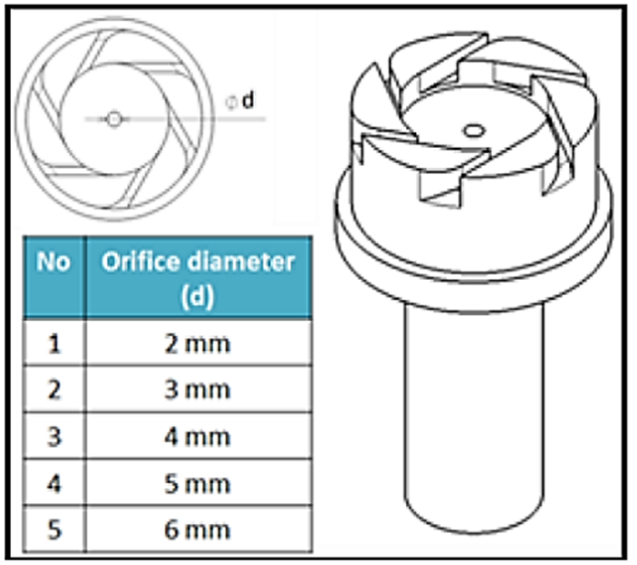

Fig. 28. The RHVT orifice dimensional change [14]

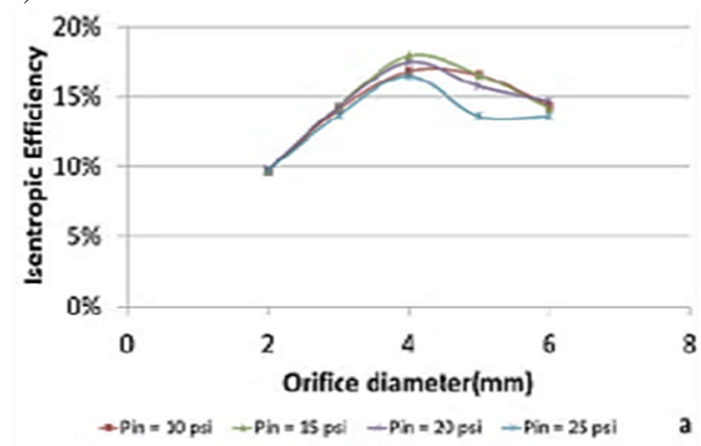

b)

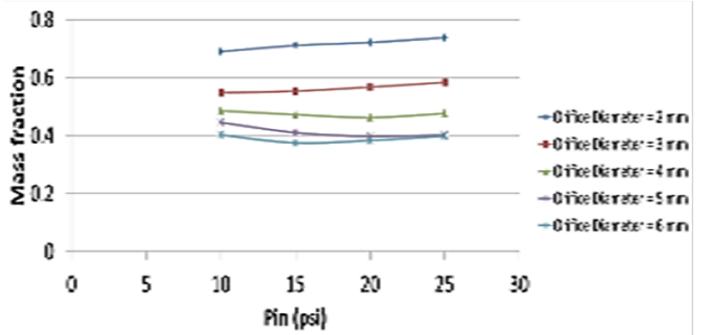

Fig. 29. The isentropic efficiency and the hot mass fraction variation with orifice size [14]

\subsection{The vortex tube shape configuration}

The first part of the VT is the swirling chamber that usually contains a circular cylinder with a specified depth, the RHVT performance optimization through the change in its chamber size is handled by S. Rafiee and M. Sadeghiazad (2016) [1] and all other dimensional parameters kept constant through CFD simulation via the finite volume approach using three turbulence models: the standard $K-\varepsilon$, the RNG $K-\varepsilon$ and the Reynolds stress (Figure 30).

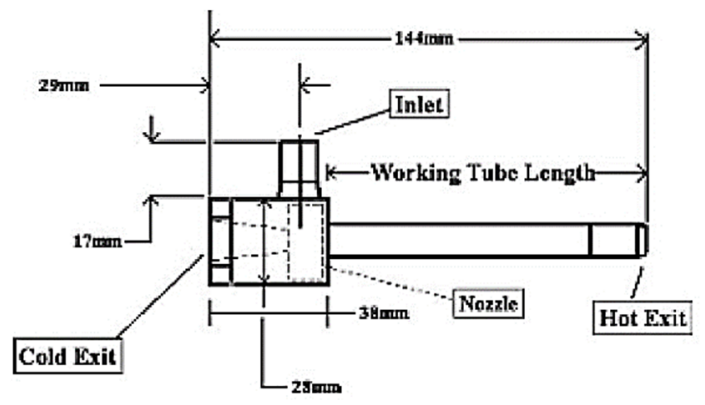

Fig. 30. The numerical simulated VT [1]

By adopting seven selected values for the swirling chamber size is considered for simulation ranges from (5.7-13) millimeters, for a constant cold mass fraction of $(0.3)$ the optimum chamber radius for the highest flow streams temperature difference is (11) $\mathrm{mm}$ noticing that this size has the maximum obtained swirling tangential velocity which will produce more efficient flow separation. 
The VT length and cold port exit size optimization for a straight tube with the variable number of inlets is performed by A. Moraveji and D. Toghraie (2017) [15] numerically by utilizing the standard K- $\varepsilon$ model considering the compressed methane as the fluid type and treated as an ideal gas. The hot stream temperature increases with increased cold tube size noticing that the inlets port rise is positively affecting the hot stream temperature (Figure 31a), also the same criteria are obtained for the cold stream mass flow rate that is increased in the same manner (Figure 31b).

While the effect of increasing the RHVT length has a slightly adverse effect on the hot to the cold mass flow fraction for a constant cold tube size (Figure 32).

Straight diverged VT with a changeable taper angle $(\theta)$ at the tube exit from (0-12) degree (Figure 33) is investigated by M. Hamdan, S. Al-Omari, and A. Oweimer (2018) [16] experimentally. The tests were conducted for the VT in order to optimize the VT length, diameter at a variable inlet air pressure that is utilized for both heating and cooling processes. The optimum taper angle for the best flow separation is the (0) degree, when this degree is increased the secondary circulated flow will be faded in RHVT resulting in a poor flow separation process.
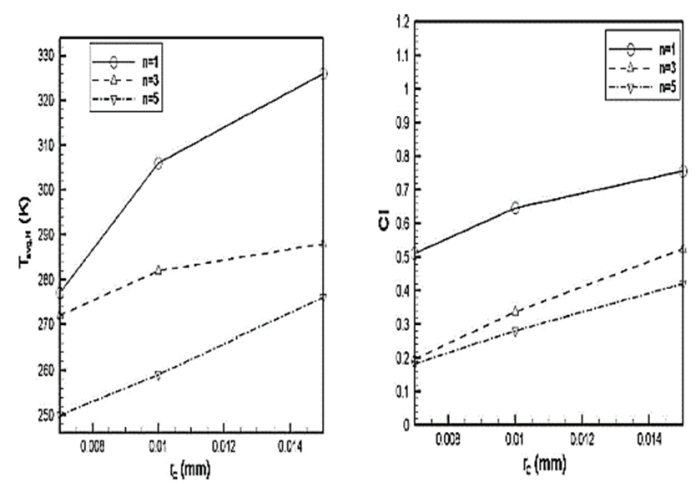

Fig. 31. The effect of the cold tube size on the hot and cold flow streams [15].

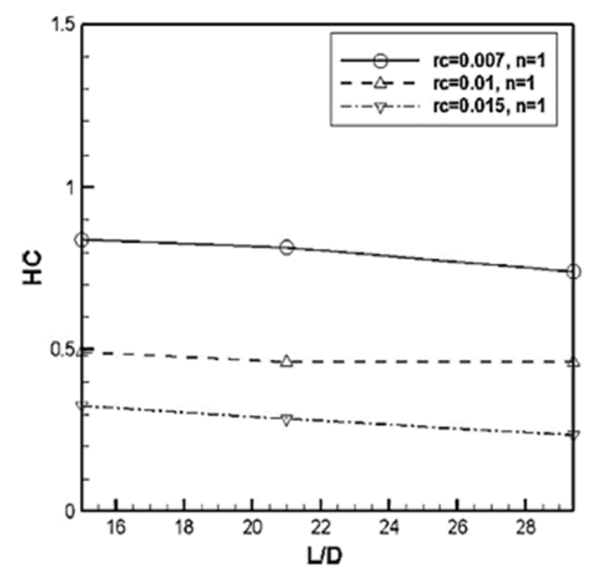

Fig. 32. The hot/cold mass flow ratio change with increased VT length [15]

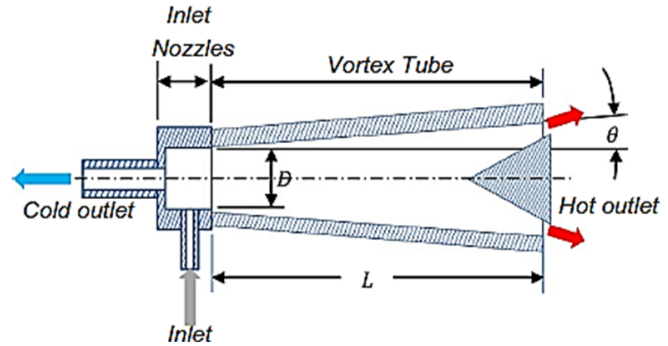

Fig. 33. The VT with taper angle shape [16].

The incorporation of various-shaped contraction zones at the VT near the cone exit valve is conducted computationally by A. Bazgir, A. Heyderi and N. Nabhani (2019) [17] using the RNG K- $\varepsilon$ turbulence model. With the adoption of circular, parallelogram, rectangular, square, trapezoidal and triangle smooth contraction (Figures 34 a-f), these contraction zones will produce stagnation flow points that increased the flow temperature profile is increased highly for the parallelogram contraction shape and the lowest in the rectangular contraction. a)

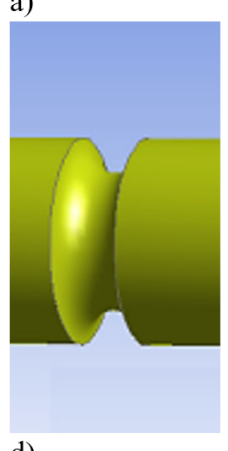

d)

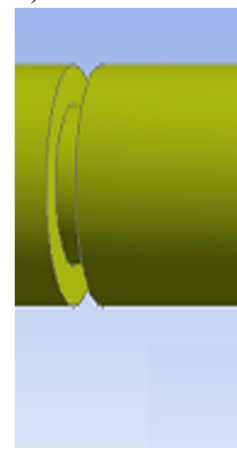

b)

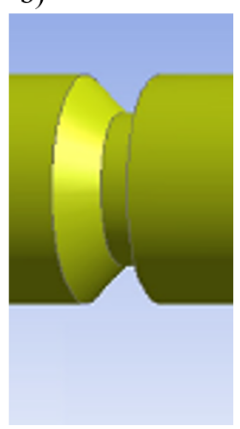

e) c)

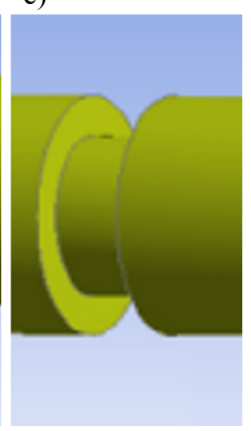

f)
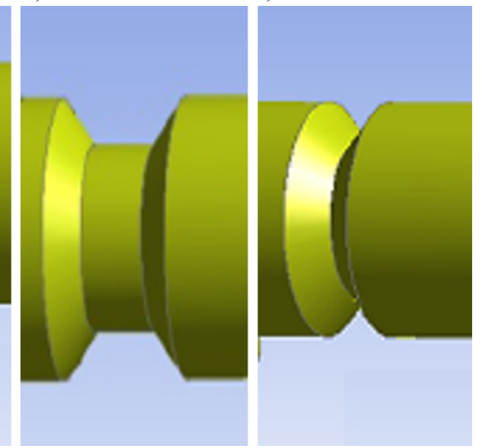

Fig. 34. The contraction zone shapes: a) circular, b) parallelogram, c) rectangular, d) square, e) trapezoidal, f) triangle [17]

One of the most frequently investigated parameters that have been thoroughly studied by the researchers is the ratio of the VT length to its size (L/D) for various profiles shapes, F. P. Branco, E. D. Buchelt, F. M. Barbosa, B. P. Rosa, and D. J. Laporte (2018) [18] has examined this parameter change experimentally on the thermal energy separation efficiency for a VT (Figure 35) 
with variable (L/D) ratio between (12-18) for two assigned values of the VT internal diameter of ( $1 / 4$ and $3 / 8$ inch), respectively when the compressed air with various inlet pressure range from (1-2.5) bar is separated thermally within the VT.

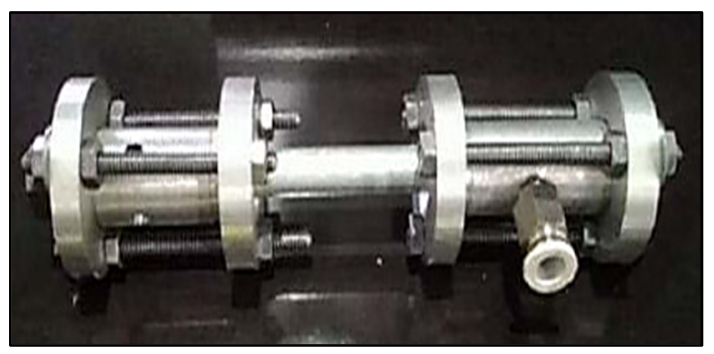

Fig. 35. The tested VT prototype [18]

The aimed target of the researchers is to calculate the cold flow mass fraction $(\mu \mathrm{c})$ in terms of the mass flow rates for both of the separated flows via equation (1) as follows:

$$
\mu_{\text {cold }}=\frac{m_{\text {cold }}}{m_{\text {total }}},
$$

where the terms ( $m_{\text {cold }}$ and $\left.m_{\text {total }}\right)$ represent the cold flow and the total air mass flow rates that are calculated from equations (2, 3 and 4$)$ according to the change in the hot and cold flow densities within the VT as follows:

$$
\begin{gathered}
m_{\text {cold }}=(v A \rho)_{\text {cold }}, \\
m_{\text {hot }}=(v A \rho)_{\text {hot }}, \\
m_{\text {total }}=m_{\text {cold }}+m_{\text {hot }} .
\end{gathered}
$$

The obtained results denoted that the cold flow temperature change is increasing with increased (L/D) ratio for a constant tube size (Figure 36a) with better enhancement in its value when the VT diameter is raised from (1/4 to 3/8 inch) (Figure 36b).

When studying the cold flow mass fraction dependency on the (L/D) rise with the variation of the flow inlet pressure (Figure $37 \mathrm{a}$ and $\mathrm{b}$ ), the optimum value that achieved the maximum increase in $\left(\mu_{\text {cold }}\right)$ is when the (L/D) equals to (15 and 12) for the tube diameters of (3/8" and 1/4") both detected at an inlet pressure of (2) bar, respectively.

The convergent-divergent type RHVT working with ideal compressed air (Figure 38) with (6) inlet nozzles is analyzed computationally by L. Zangana and R. Barwari (2020) [19] using the standard $K-\varepsilon$ turbulence model in the FLUENT software and validated experimentally considering the constant inlet pressure and cold flow mass fraction, by comparing the results with a traditional VT type, the case is estimated as steady-state and an adiabatic with the neglection of the frictional effect, the minimum cold temperature flow location of the VT is analyzed with the variation of the throttling diameter size from (2.5-3.5) $\mathrm{mm}$.
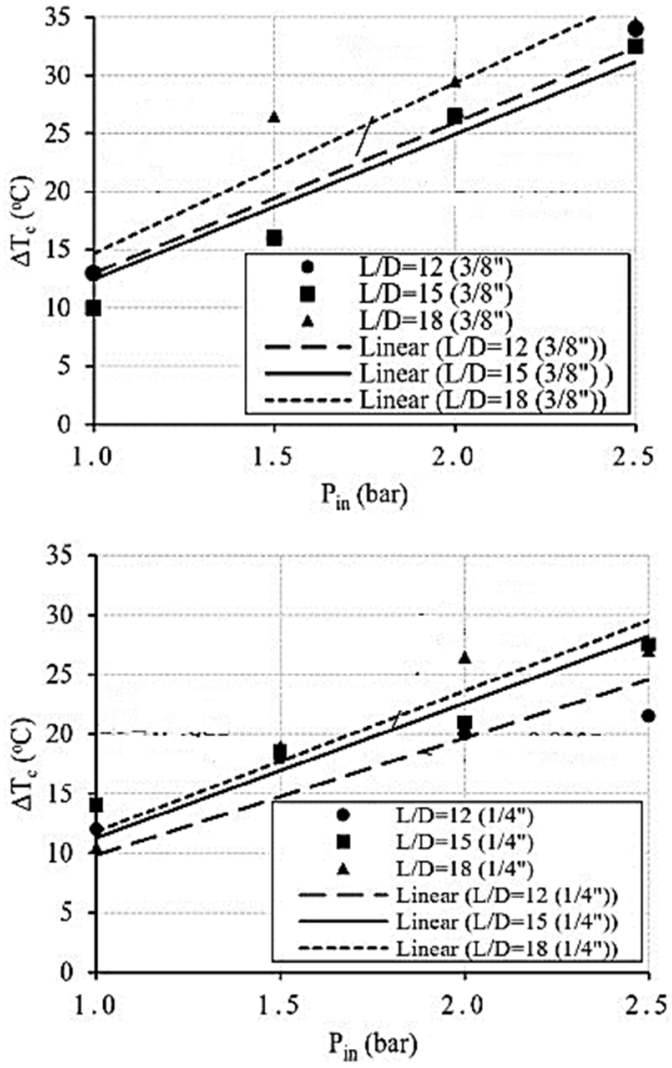

Fig. 36. The cold flow temperature difference with respect to variable (L/D) ratio [18]
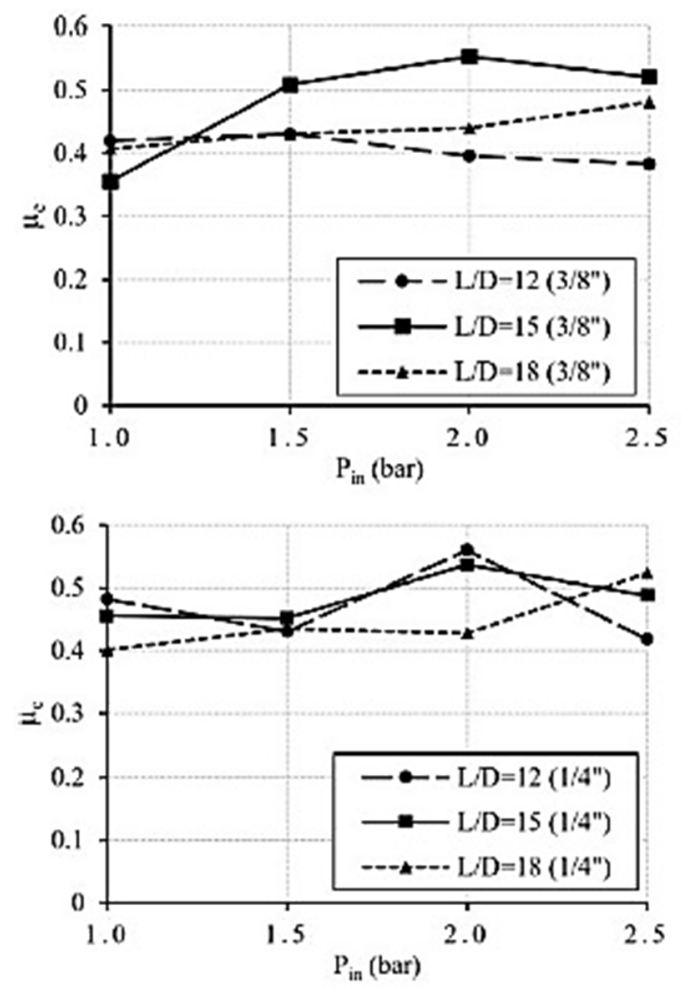

Fig. 37. The change of cold mass fraction for various (L/D) ratio and inlet pressure [18] 


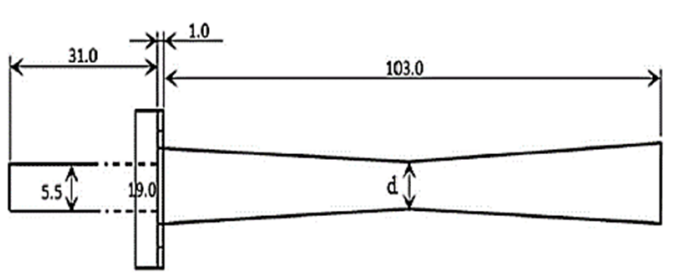

Fig. 38. The convergent-divergent RHVT [19]

The results indicated that the minimum throat size achieved the minimum cold temperature to be in the cold exit location, also the convergent-divergent VT utilization resulted in more temperature drop in the cold flow and created a higher hot flow pressure which is drawn to the hot exit region (Figures $39 \mathrm{a}$ and $\mathrm{b}$ ).

a)

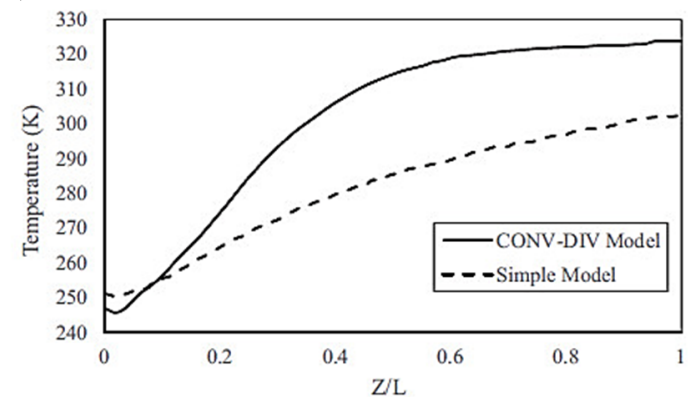

b)

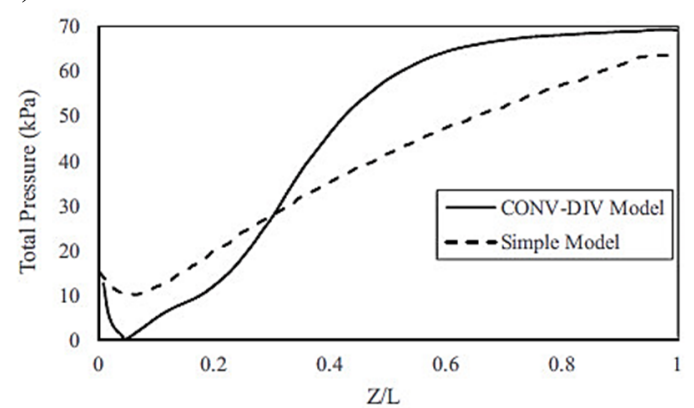

Fig. 39. The convergent-divergent RHVT [19]

The effect of variation in the contraction linear slope angle from (0-9) in the convergent type RHVT (Figure 40) has been investigated numerically and experimentally by S. Rafiee, M. Sadeghiazad, and N. Mostafavinia (2015) [20] as a combination factor with the VT cold flow orifice size variation from $(8-9.5 \mathrm{~mm})$ defining the inlet and outlet boundary conditions on pressure-based values, the finite volume solution approach in the numerical simulation is adopted.

This numerical method has achieved a high rate of convergence (below 5\%) when the results are validated with the experimental results for both hot and cold flow with various contraction angle values (Tables 2 and 3).

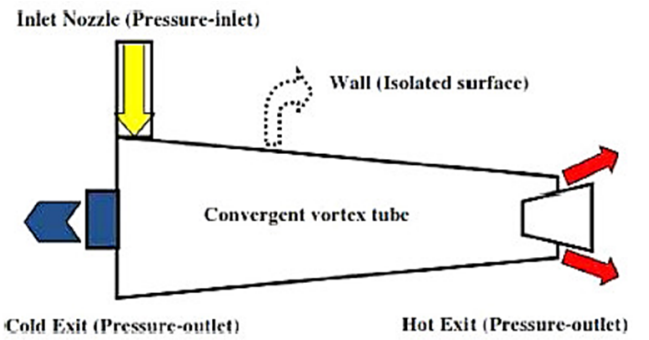

Fig. 40. The convergent utilized VT [20]

Tab. 2. Validation of numerical results 1/2 [20]

\begin{tabular}{cccc}
\hline Angle [deg] & $\Delta \mathrm{T}_{\mathrm{C}}$ Exp. [K] & $\Delta \mathrm{T}_{\mathrm{C}}$ Num. [K] & Disagreement [\%] \\
\hline$\beta=0$ & 21.1 & 20.19 & 4.31 \\
\hline$\beta=1$ & 22.54 & 22.85 & 1.37 \\
\hline$\beta=3$ & 25.07 & 24.84 & 0.91 \\
\hline$\beta=5$ & 27.86 & 26.85 & 3.62 \\
\hline$\beta=7$ & 26.25 & 26.67 & 1.6 \\
\hline$\beta=9$ & 18.32 & 18.03 & 1.58 \\
\hline
\end{tabular}

Tab. 3. Validation of numerical results 2/2 [20]

\begin{tabular}{cccc}
\hline Angle [deg] & $\Delta \mathrm{T}_{\mathrm{C}}$ Exp. [K] & $\Delta \mathrm{T}_{\mathrm{C}}$ Num. [K] & Disagreement [\%] \\
\hline$\beta=0$ & 23.42 & 22.91 & 2.17 \\
\hline$\beta=1$ & 25.19 & 25.24 & 0.19 \\
\hline$\beta=3$ & 28.25 & 27.84 & 1.45 \\
\hline$\beta=5$ & 29.56 & 28.31 & 4.22 \\
\hline$\beta=7$ & 27.45 & 25.85 & 5.82 \\
\hline$\beta=9$ & 25.98 & 26.32 & 1.3 \\
\hline
\end{tabular}

The most desired convergence angle $(\beta)$ that achieved the highest difference in both hot and cold flows streamlines temperatures is the (5) degree angle (Figures $41 \mathrm{a}$ and $\mathrm{b}$ ) noticing that the increased cold mass fraction up to (0.7) and (0.4) achieves the maximum thermal efficiency for the RHVT.

The application of a guided vane flow rectifier within the main RHVT body that has four entrance nozzles is performed numerically by $\mathrm{R}$. $\mathrm{Li}, \mathrm{Z}$. Hu, and Y. Gao (2019) [21] in order to observe the variations in the axial and the tangential velocity components with a variable number of the guided vanes ranging from (3-9) (Figure 42) where the adjusted rectifier is positioned just before the VT conical hot exit valve.

With the adoption of the realizable $K$ - $\varepsilon$ turbulence model in the numerical solution, the axial velocity variation with the increased number of guided vanes is increasing in the central region of the VT (Figure 43) since the effective flow area will be reduced while it is reduced in the outer radial location due to the effect of the guided vanes through the increased swirling flow in the tangential direction. 
a)

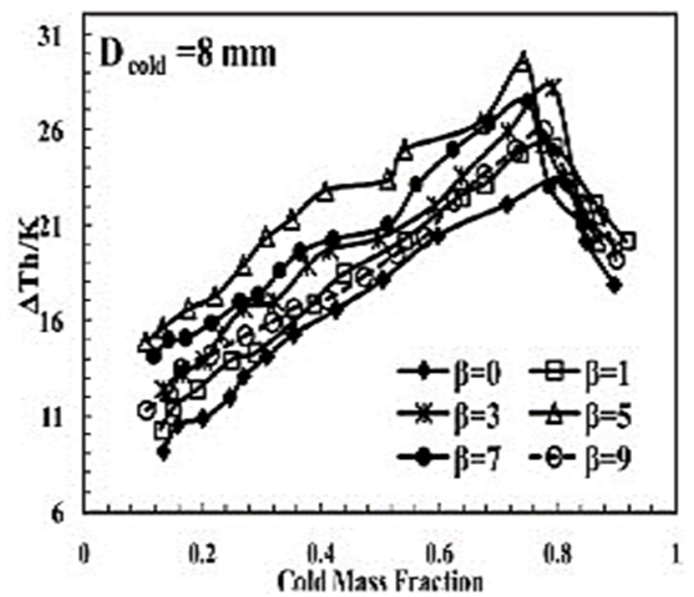

b)

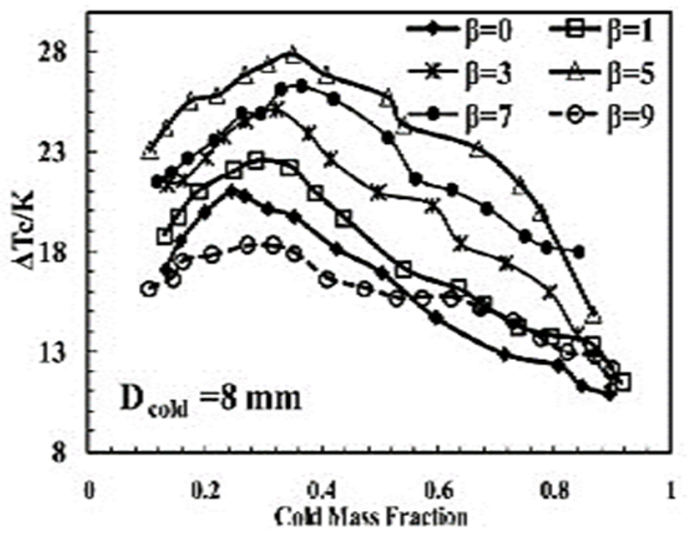

Fig. 41. The developed temperature variation with increased convergence angle [20]

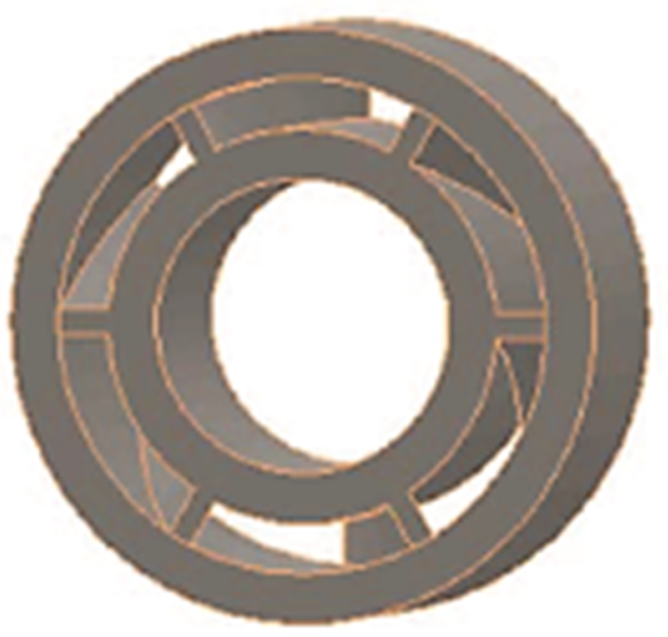

Fig. 42. The installed vane rectifier [21]

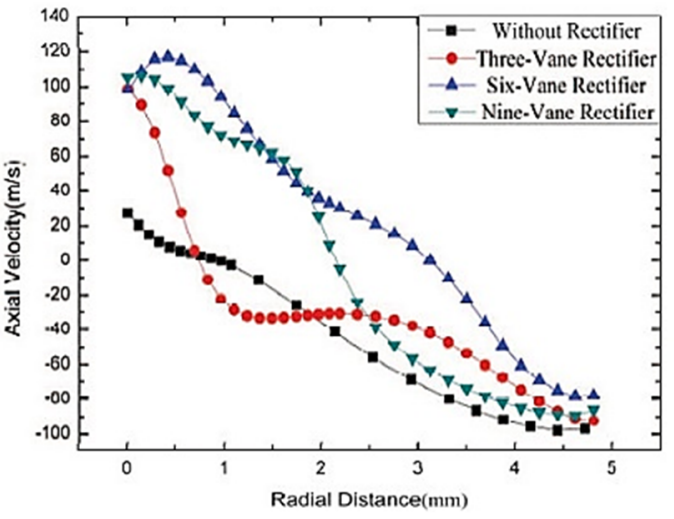

Fig. 43. The axial flow velocity variation with No. of guided vanes [21]

This above-mentioned parameter will affect the hot flow temperature difference at a higher rate than the cold flow temperature change (Figures $44 \mathrm{a}$ and $\mathrm{b}$ ) as the cold mass flow fraction is increased noticing that the utilizing of the three guided vanes rectifier has achieved the maximum VT performance.

a)

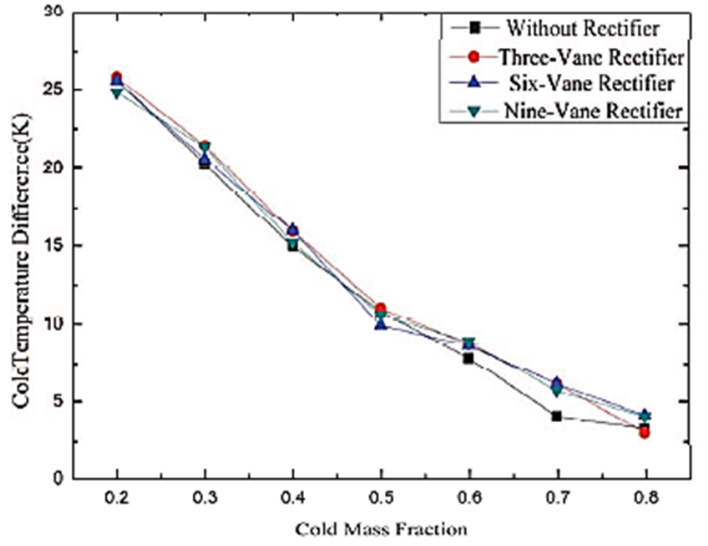

b)

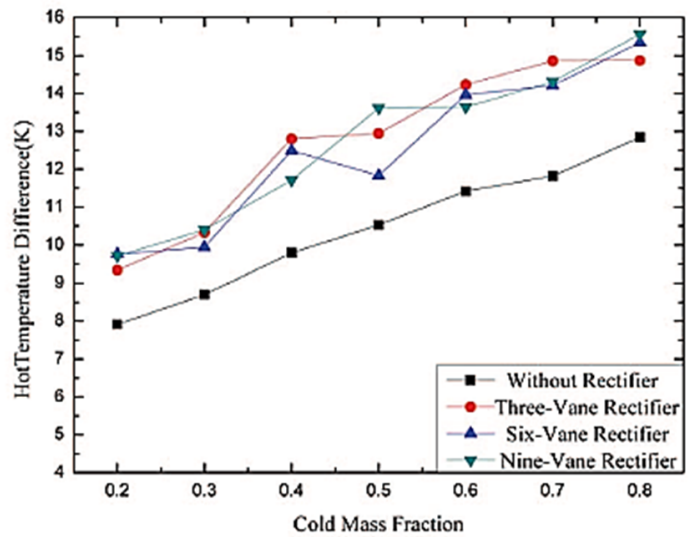

Fig. 44. The hot and cold temperature difference change with the number of guide vanes [21] 
Further improvement that resulted in the RHVT separation efficiency increasing is the application of the circular-curved VT path with different curvature bending angle (Figure $45 \mathrm{a}$ and $\mathrm{b}$ ) which is performed numerically and experimentally by S. Rafiee, S. Ayenehpour, and M. Sadeghiazad (2016) [22] using the Reynolds stress turbulence model in the FLUENT software.
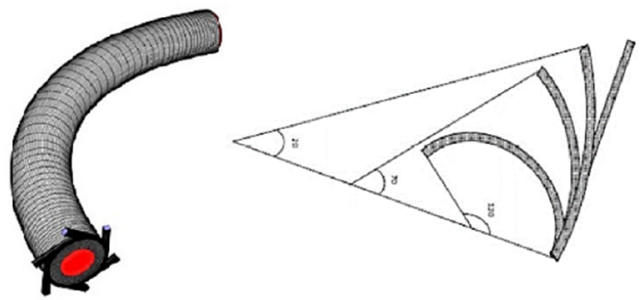

Fig. 45. The curved path VT [22]

With changing the counter flow VT bending angle from $\left(0\right.$ to $\left.120^{\circ}\right)$ when manufacturing the energy separation device while the other main dimensions are kept constant except the number of nozzles are changed from (2-6) and utilizing the truncated shape of the control valve at the hot flow exit port, the compressed air is considered the utilized fluid in both of numerical simulation and the experimental testing in the straight and the curved VT in order to compare the obtained results.

The choosing of the suitable grid mesh distribution of the numerical solution (Figure 46) is done via the performing of the independence tests to monitor the cold separated flow temperature difference variation with respect to the assigned average flow unit cell volume where the researchers considered it's least affecting value is within $\left(0.041 \mathrm{~mm}^{3}\right)$ that corresponds to $1,325,000$ accounts of cells.

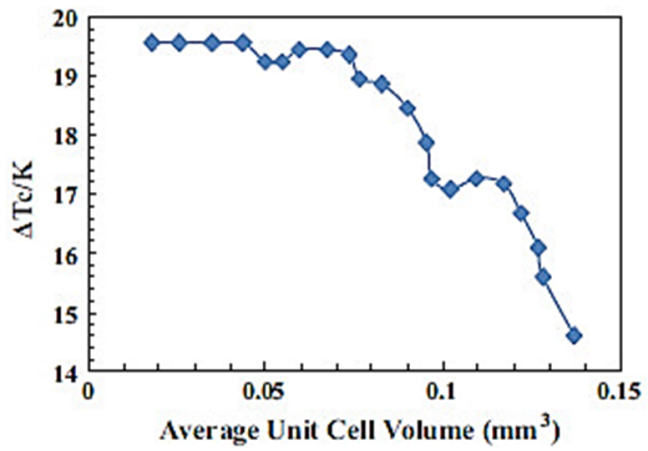

Fig. 46. The mesh dependency test results [22]

The obtained results for the variation of the curved VT bending angle (Figure 47) demonstrates that the optimum bending angle of $\left(10^{\circ}\right)$ achieves the highest rate for the cold flow temperature difference when utilizing two nozzles in the VT that lies within a moderate range of cold mass fraction between (0.2-0.6), respectively.

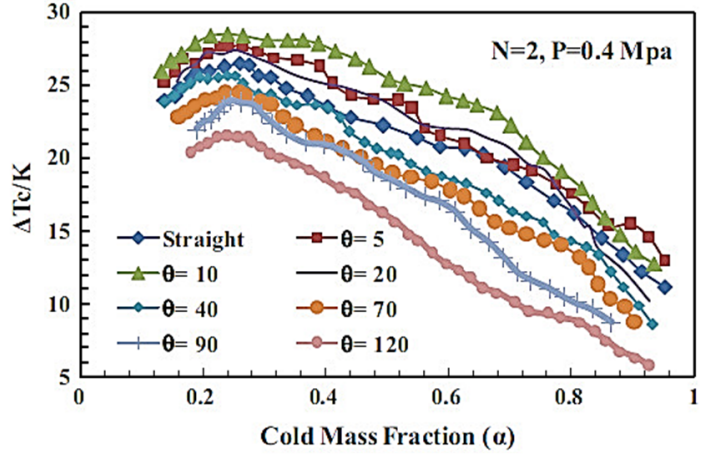

Fig. 47. The effect of the curved VT bending angle as compared with the straight VT type [22]

The detected numerical simulation results validation with the experimental tests performed by the researchers (Table 4) shows that a maximum percentage error within $(6 \%)$ is detected between the CFD results and the experiments reading data for the cold flow temperature difference.

Tab. 4. The percentage error between the CFD and the experimental results [22]

\begin{tabular}{lccc}
\hline Model & $\begin{array}{c}\Delta \mathrm{T}_{\mathrm{C}} \\
\text { experimental } \\
{[\mathrm{K}]}\end{array}$ & $\begin{array}{c}\Delta \mathrm{T}_{\mathrm{C}} \\
\mathrm{CFD} \\
{[\mathrm{K}]}\end{array}$ & $\begin{array}{c}\text { Difference between } \\
\text { experimental and } \\
\text { CFD results [\%] }\end{array}$ \\
\hline Straight Case (f) & 26.27 & 25.98 & 1.1 \\
\hline$\theta=5$ Case(d) & 26.98 & 26.84 & 0.51 \\
\hline$\theta=10$ Case(x) & 28.56 & 27.79 & 2.69 \\
\hline$\theta=20$ Case(r) & 27.41 & 26.63 & 2.84 \\
\hline$\theta=40$ Case $(\mathrm{y})$ & 25.69 & 24.74 & 3.69 \\
\hline$\theta=70$ & 24.54 & 23.59 & 3.87 \\
\hline$\theta=90$ & 23.97 & 22.54 & 5.96 \\
\hline$\theta=120$ & 21.53 & 21.07 & 2.13 \\
\hline
\end{tabular}

The incorporation of a second mixing chamber with the same number and characteristics of injection nozzles downstream the VT (Figure 48) is implemented by N. Pourmahmoud, F. S. Azar, and A. Hassanzadeh (2014) [23] via the numerical solution in order to investigate its effect on the optimization of the VT length.

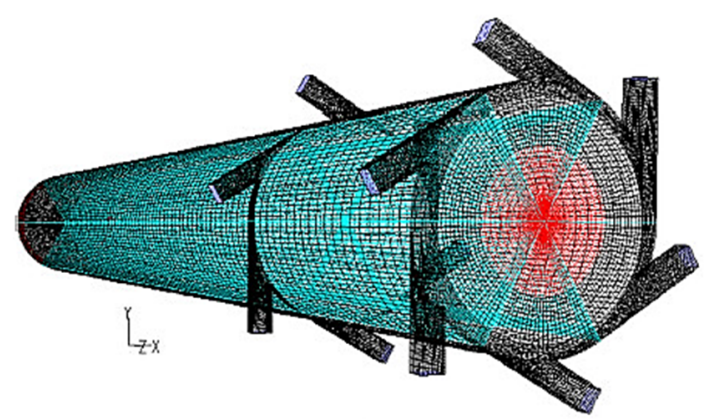

Fig. 48. The modified VT geometry [23] 
The researchers considered the standard $K$ - $\varepsilon$ turbulence model for the solution of the steady-state three-dimensional computational domain within the modified VT where its characteristic dimensions are selected (Table 5) to concise with the previously performed experimental test by H.M. Skye, G.F. Nellis, and S.A. Klein (2006) [24].

Tab. 5. The VT adopted dimensions [24]

\begin{tabular}{ll}
\hline Measurement & Value \\
\hline Working tube length & $106 \mathrm{~mm}$ \\
Working tube I.D. & $11.4 \mathrm{~mm}$ \\
Nozzle height & $0.97 \mathrm{~mm}$ \\
Nozzle width & $1.41 \mathrm{~mm}$ \\
Nozzle total inlet area (An) & $8.2 \mathrm{~mm}^{2}$ \\
Cold exit diameter & $6.2 \mathrm{~mm}$ \\
Cold exit area & $30.3 \mathrm{~mm}^{2}$ \\
Hot exit diameter & $11 \mathrm{~mm}^{2}$ \\
Hot exit area & $95 \mathrm{~mm}^{2}$ \\
\hline
\end{tabular}

In order to the precise adoption of the computational domain mesh grid, the performed numerical solution accuracy did not greatly affected when the unit computational domain cell volume below $\left(0.0257 \mathrm{~mm}^{3}\right.$ ) (Figure 49) that correspond to mesh density of (287000) cells.

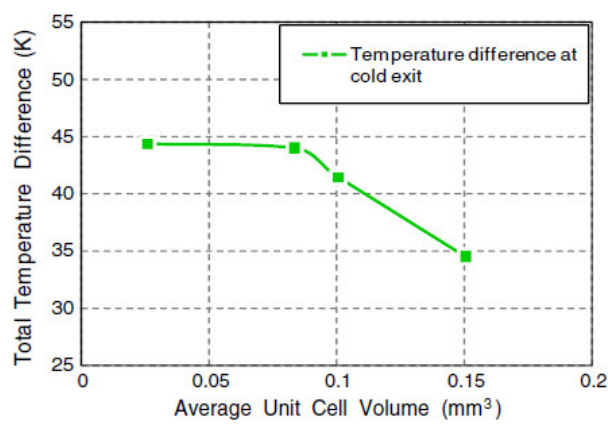

Fig. 49. The mesh dependence test [23]

In order to the precise adoption for the most accurate value of the cold flow mass fraction that achieves the lowest deviation of the numerical solution results as compared with previous literature results. The researchers have specified its value to $(0.3)$ where the minimum percentage error is obtained (Figures $50 \mathrm{a}$ and $\mathrm{b}$ ) for both of the thermally separated flows.

The effect of the second installed mixing chamber with different axial location (Z) from the first mixing chamber along the VT length shows that the closer gap between the two chambers is efficient for the cooling purpose of the VT as it reduces the minimum value of the cold air flow (Figure 51a) while the chambers linear space increasing will contribute at a higher rate of the hot flow temperature rise (Figure 51b).

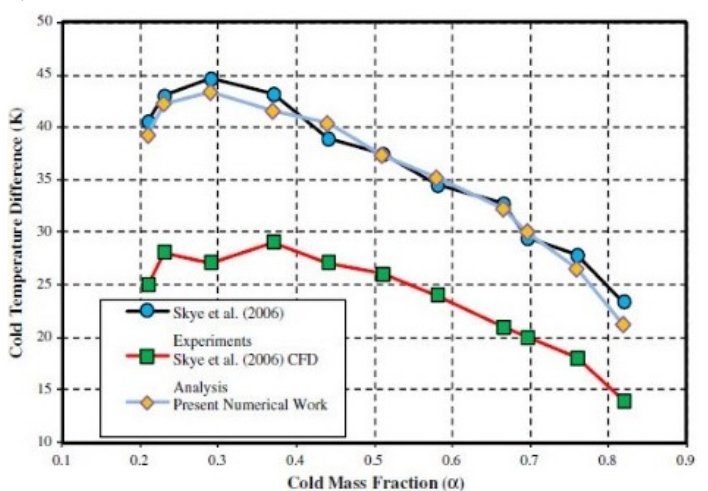

b)

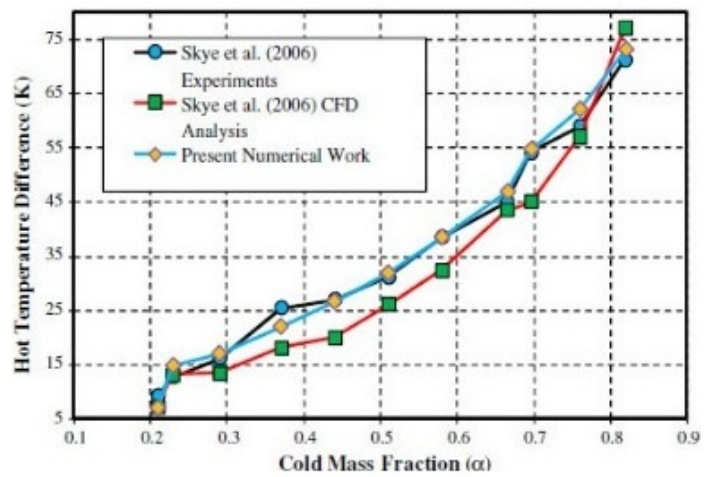

Fig. 50. The numerical solution comparison with previous work [23]

a)

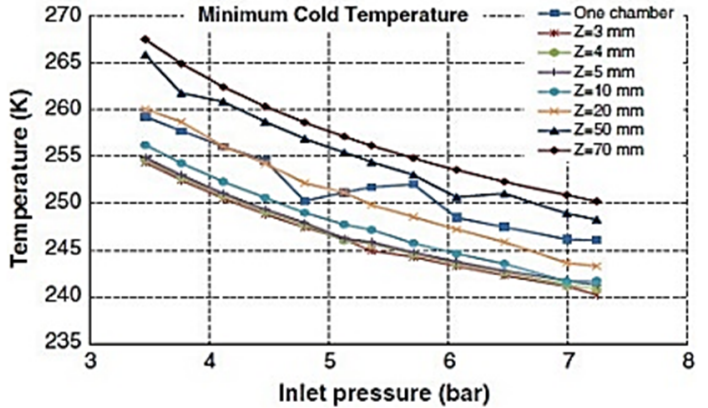

b)

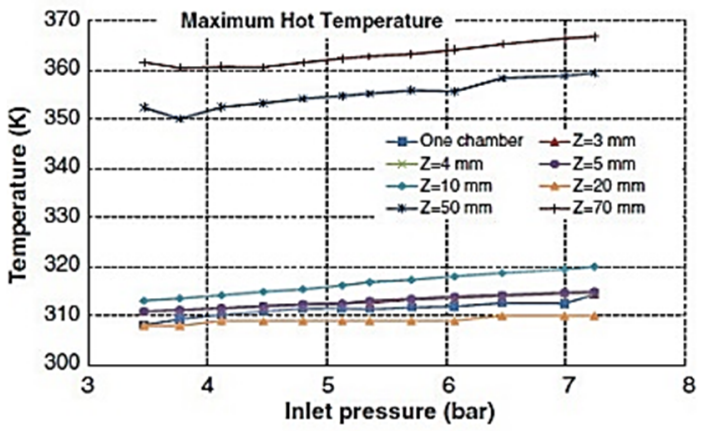

Fig. 51. The effect of linear space between the VT chambers [23] 
A novel VT design change by converting its hot separated flow direction from the axial to the annular direction pattern is implemented by M. Sadi, and M. Farzaneh-Gord (2014) [25] where the hot flow will further increase the heat loss (Figure 52) from the VT outer wall and enhance the cooling efficiency of the AVT.

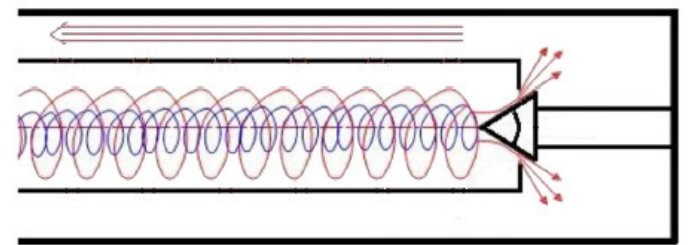

Fig. 52. The annular vortex tube [25]

The researchers followed the thermodynamics energy balance approach within the AVT for the evaluation of the cold flow mass fraction and the isentropic efficiency $\left(\eta_{i s}\right)$ according to the experimental data that are obtained from the testing of the designed VT considering the compressed air to be isothermally expanded within the AVT so that its calculated efficiency will be:

$$
\eta_{\text {is }}=\frac{\left(T_{\text {in }}-T_{\text {cold }}\right)}{T_{\text {in }}\left(1-\left(\frac{P_{a t m}}{P_{\text {in }}}\right)^{\gamma / \gamma-1}\right)},
$$

where the term $(\gamma)$ represents the heat capacity ratio.

In order to evaluate this modification in the RHVT since it will affect the hot and cold flow temperature variation and also the resulted process isentropic efficiency, each of these parameters is compared (Figures $53 \mathrm{a}-\mathrm{c}$ ) and showed that the temperature of the cold and hot flow is enhanced for the AVT as well as the isentropic efficiency.

\subsection{The conical valve configuration}

This parameter has the least studied affecting factor on the RHVT performance, unfortunately, a few works of literature have covered it. Experimental testing on the RHVT performance is performed by N. Ismail, W. Wisnoe and M. Remeli (2014) [26] using two different kinds of the hot exit control valve that are the conical and the truncated with their primary dimension setting (Figure 54) in addition to the two other parameters including swirling chamber depth and the orifice diameter change.

For the various magnitude of the flow inlet pressure, the conical shape valve has performed a higher cooling performance from the truncated shape (Figure 55). An overall conclusion is the conical valve shape has less effect among other mentioned parameters.

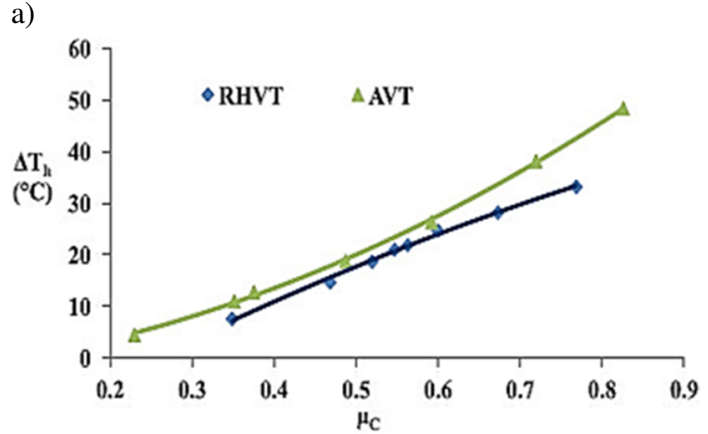

b)

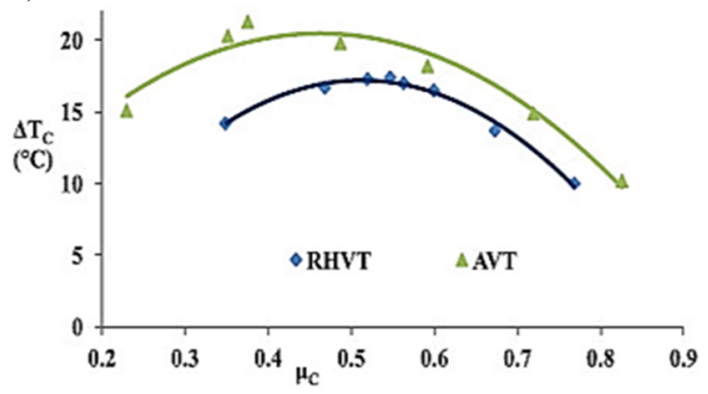

c)

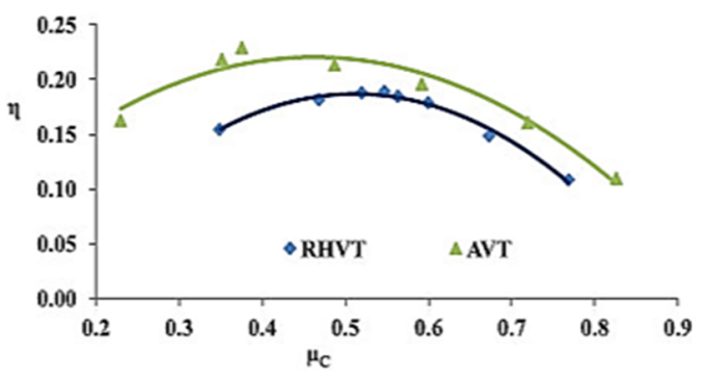

Fig. 53. The comparison between the Vortex tubes [25]
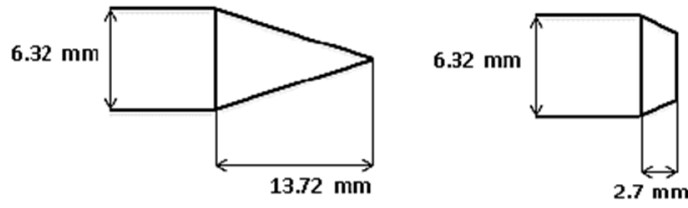

CV1

$\mathrm{Cv} 2$

Fig. 54. The utilized conical valves [26]

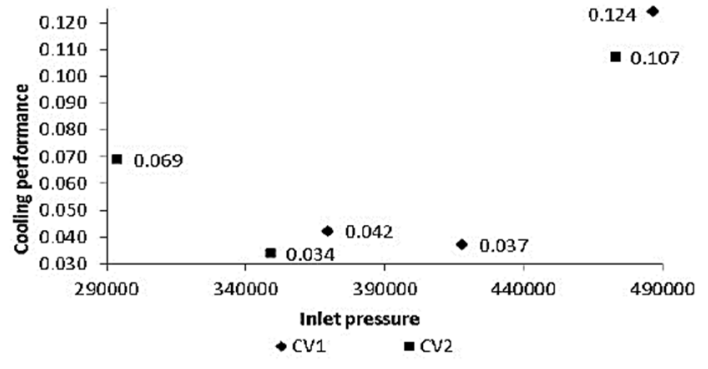

Fig. 55. The cooling performance comparison of the control valve shapes [26] 
More exit control valve shapes in the RHVT including the spherical and the rectangular as well as the conical (with variable cone angle) and the truncated configurations (Figure 56) are investigated computationally by M. Abdul Qyyum, A. Noon, F. Wei and M. Le (2019) [27] using the standard $K-\varepsilon$ model in the ICEM CFD software using the hexagonal meshing method. The truncated shape control valve has achieved the best results for the temperature difference for constant inlet conditions with the variation of the cold mass fraction which is followed by the cone, the rectangular and the spherical shapes.
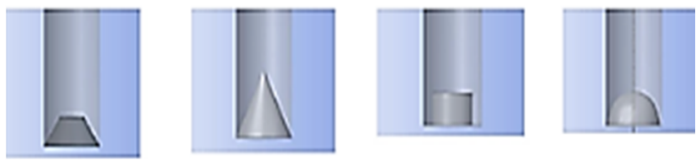

Fig. 56. The adopted exit control valve shapes [27]

The conical shape cone angle variation effect from (30-90) degree for a straight and a (4) degree diverged tube type on the exergy loss and efficiency of the RHVT is investigated by K. Devade and A. Pise (2016) [28] experimentally, the most affecting cone valve angles are the (30\&90) degree which will produce higher maximum exergy efficiency of the hot flow region (Figure 57).

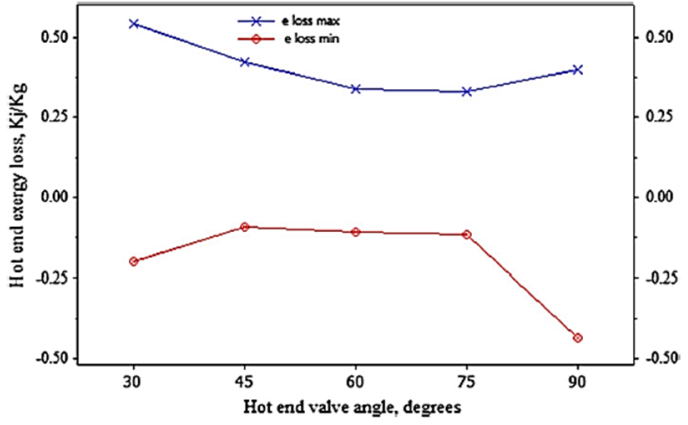

Fig. 57. The hot flow exergy loss variation with the cone angle [28]

G. M. P. Yadav, P. M. Reddy, and B. U. M. Gowd (2016) [29] developed a novel design modification to the RHVT that consists of two strategies. The $1^{\text {st }}$ modification (Figure 58) is the utilization of hollowed conical control valve in which the first separated cold flow will pass through (cold end 2), while the $2^{\text {nd }}$ modification is that the rest returned cold flow will be separated equally via a symmetrical two-way truncated separator in which the VT will produce dual vortex cold flow in the region between the hollowed conical valve and the solid separator (cold end 1).

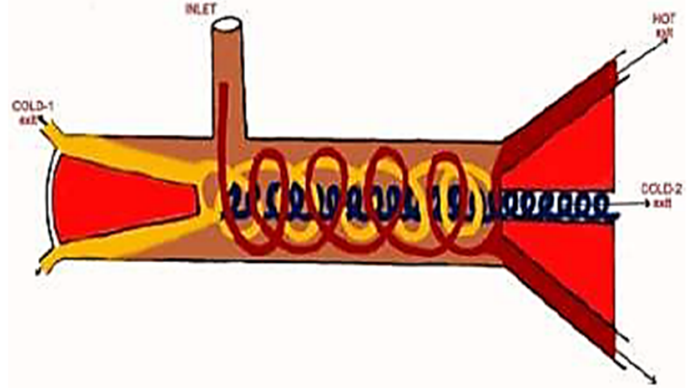

Fig. 58. The modified RHVT [29]

These two major modifications are implemented with the variation of the VT flow cones angles from $\left(35-65^{\circ}\right)$ for the hollowed conical valve and (25-55) for the solid separator valve. With the implementation of the compressed air, the VT is tested experimentally and the evaluation of the cold mass fractions is done by the adoption of the following two equations:

$$
\begin{aligned}
& \mu_{\text {cold } 1}=\frac{m_{\text {cold } 1}}{m_{\text {in }}}, \\
& \mu_{\text {cold } 2}=\frac{m_{\text {cold } 2}}{m_{\text {in }}},
\end{aligned}
$$

where the terms $\left(\mu_{\text {coldl, } 2)}\right)$ represent the cold flow mass fractions that are based on its mass flow rates within the two cold flow exit ports in the utilized control valves.

As noticed from the presented results, the cold flow mass fraction variation in both of the exit ports (Figures $59 \mathrm{a}$ and $\mathrm{b}$ ) shows that an optimum combination value for the two tapering angles that achieves the highest cold flows temperature drop with the desired corresponding cold mass flow rate where the $1^{\text {st }}$ generated cold flow maximum temperature difference is obtained at $\left(\alpha=45\right.$ and $\left.\beta=55^{\circ}\right)$ when its rate of a mass fraction within $(0.2)$, while the $2^{\text {nd }}$ generated cold flow maximum temperature drop is obtained when $(\alpha=45$ and $\beta=25^{\circ}$ ) as long as the cold mass fraction is increasing remarking that the hollowed cone valve tapering angle value assignment to $\left(45^{\circ}\right)$ will achieve the maximum allowable temperature drop for both of the generated cold flows.

The conical valve cone length is one of the geometrical parameters that have been investigated numerically and experimentally by Rafiee S., and Sadeghiazad M. (2014) [30] within a specified range equal or below $(10 \mathrm{~mm})$ when utilizing different shapes of the control valve with constant tapering angle and (L/D) ratio (Figure 60) as long as the VT nozzles number is varied from (2-6), respectively.

The numerical simulation is performed using the standard K-E turbulence model, setting the flow inlet pressure to the VT by $(0.25 \mathrm{MPa})$ and the flow exit ports are considered as a pressure far field in the boundary conditions. 
a)

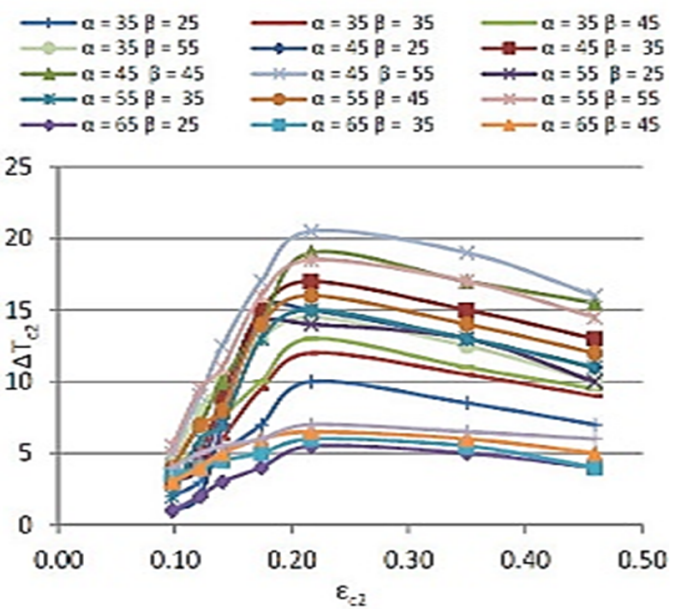

b)

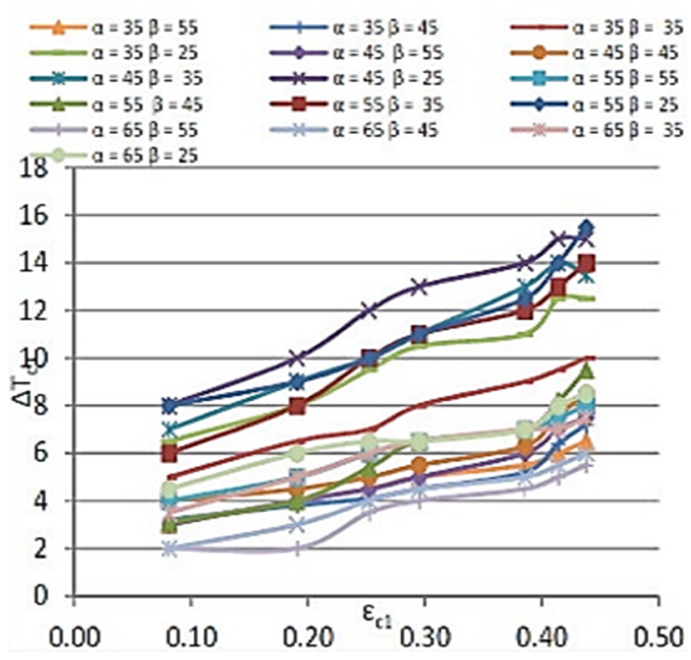

Fig. 59. The generated cold mass fractions temperature difference in the modified VT: a) the hollowed conical valve, b) $T=$ the solid separator [29]

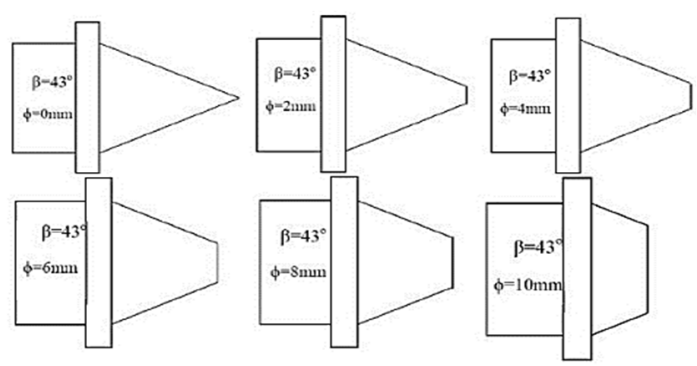

Fig. 60. The hot flow control valve shapes [30]

After the evaluation of the cold and hot flows temperature difference, the identifying of the optimum cone valve length is reached by the authors to $(6 \mathrm{~mm})$ (Figures $61 \mathrm{a}$ and $\mathrm{b}$ ) where the cold mass fraction of the total air volume equals to $(0.2$ and 0.8$)$ for the best efficient cooling or heating VT purpose. a)

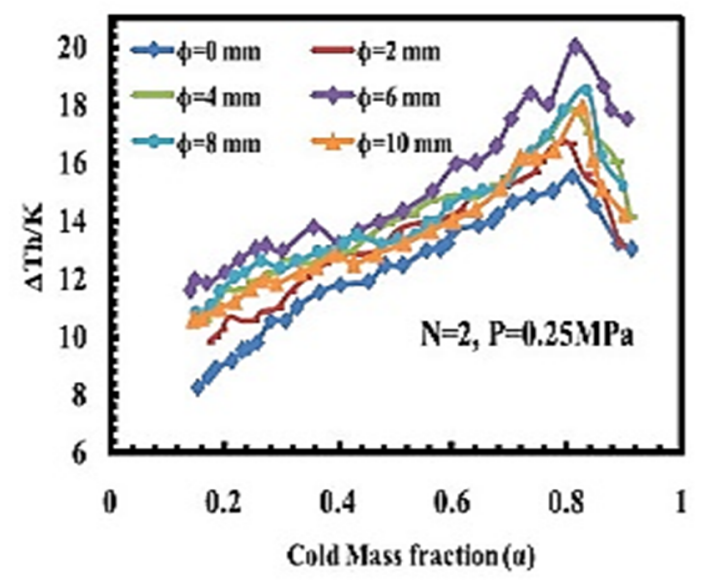

b)

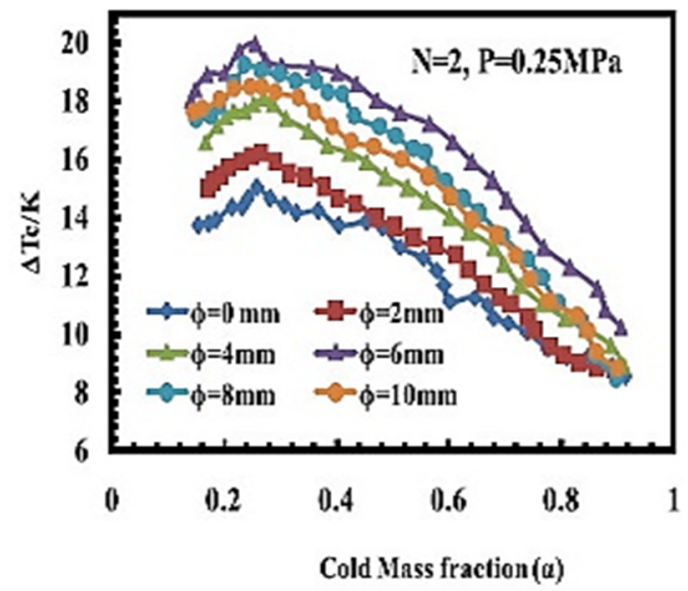

Fig. 61. The conical valve length effect on the separated flow temperature difference [30]

The achieved results from the numerical solution is validated with the experimental data results denoted that a very high rate of convergence between them does not exceed $(5 \%)$ error for the resulted cold flow temperature difference (Table 6).

Tab. 6. Numerical solution validation [30]

\begin{tabular}{cccc}
\hline Model & $\begin{array}{c}\Delta \mathrm{T}_{\mathrm{C}} \\
\text { experimental } \\
{[\mathrm{K}]}\end{array}$ & $\begin{array}{c}\Delta \mathrm{T}_{\mathrm{C}} \mathrm{CFD} \\
{[\mathrm{K}]}\end{array}$ & $\begin{array}{c}\text { Difference between } \\
\text { experimental and } \\
\text { CFD results [\%] }\end{array}$ \\
\hline$\phi=0 \mathrm{~mm}$ & 18.25 & 18.12 & $0.7 \%$ \\
\hline$\phi=2 \mathrm{~mm}$ & 21.55 & 20.88 & $3.2 \%$ \\
\hline$\phi=4 \mathrm{~mm}$ & 23.15 & 22.2 & $4.2 \%$ \\
\hline$\phi=6 \mathrm{~mm}$ & 27.21 & 26.8 & $1.5 \%$ \\
\hline$\phi=8 \mathrm{~mm}$ & 25.5 & 24.6 & $3.5 \%$ \\
\hline$\phi=10 \mathrm{~mm}$ & 26.15 & 25.2 & $3.6 \%$ \\
\hline
\end{tabular}




\section{CONCLUSIONS}

The most important conclusions that are reached from the reviewing of the prescribed literature concerning the effective Ranque Hilsch vortex tube geometrical dimensioning parameters can be summarized as follows.

1. Among the various tube cross-sectional shapes, the most efficient energy separation process is achieved with the trapezoid and the rectangular cross-sectional shapes with the incorporation of their dimension's aspect ratio as an optimization factor.

2. The most adversely affecting factor that reduces the energy separation process is the divergent tube profile with any inclination angle while the convergent-divergent type with symmetrical equal sections achieved an improved energy separation efficiency.

3. Concerning the nozzles path shape and characteristics, the helically profile shape nozzles by adjusting their helical profile pitch value represents a good option for the increased VT performance, especially when utilizing a moderate number of injection nozzles equals or higher than three. Also, the utilization of the converged type nozzles path with the adjustment of its contraction dimensional ratio represents a second affecting parameter on the VT efficiency.

4. The application of the parallelogram flow contraction shape within the VT as well as the truncated control valve shape can also serve to the same desired target.

The following recommendations are suggested to be investigated numerically and experimentally.

1. An additional RHVT nozzle configuration that could be studied such as the application of the threaded or internal finned for both straight (including constant and converged area) and helical nozzles with different cross-sectional area shapes.

2. Although the VT orifice is a very important region that governs both of the separated passing hot and cold flow, unfortunately, the most research work on this parameter concentrated only on the orifice optimum diameter and its relation with the VT length to its diameter ratio. In addition, most of the researchers ignored its internal configuration of the orifice considering it as a straight tube without any suggested improvement in its shape characteristics.

3. The optimization of the orifice dimensions with respect to the nozzles flow entrance to the swirling chamber shape characteristics are ignored in which indeed further intensive research can be further conducted.

4. The incorporation of the helical twisting VT for both of straight and/or convergent-divergent profiles with the application of the contraction zone within the VT, also the utilization of the non- straight (curved) shape profile convergentdivergent VT with the variation of its throat location.

5. The modification of the circular tube cross-section to an elliptical shape type represents an additional investigation parameter for the RHVT separation efficiency.

6. Studying the half-elliptical shape control valve effect on the VT performance and also studying the optimum ratio of the cone valve of the main vortex tube lengths for the pre-investigated VT crosssectional shapes in addition to the investigation of the optimum flow stagnation position inside the VT can be studied numerically and/or experimentally.

7. Also, the studying of the truncated shape control valve shape edge angle variation effect on the flow separation represents an additional geometrical parameter that can be studied thoroughly.

8. The observation of the response of the various industrial and natural Refrigerants in the liquid and/or the vapor phases behavior to the prescribed RHVT geometry factors.

\section{Nomenclature}

\section{Symbols}

$L \quad$ - Vortex tube length

$D$ - Vortex tube inner diameter

$m$ - Mass flow rate

$\mu$ - Cold flow mass fraction

$\alpha$ - Hollowed conical valve cone angle

$\beta$ - Solid flow separator tapering angle

$\varphi$ - Hot flow control valve length

\section{Acronyms}

AVT - Annular Vortex Tube

CFD - Computational Fluid Dynamics

COP - Coefficient of Performance

RHVT - Ranque-Hilsch Vortex Tube

\section{References}

1. Rafiee S., Sadeghiazad M (2016). Three-Dimensional CFD Simulation of Fluid Flow inside a Vortex Tube on Basis of an Experimental Model- The Optimization of Vortex Chamber Radius Proceedings example. International Journal of Heat and Technology, Vol. 34, Issue 2, pp. 236-244

2. Manimaran R. (2016). Computational analysis of energy separation in a counter-flow vortex tube based on inlet shape and aspect ratio. Energy, Vol. 107, pp. 17-28

3. Fidus F., Mathew R., Nidhan A., Mohan S., J. Chandran (2017). Computational Analysis of Vortex Tube with Different Inlet Shapes. Global Research and Development Journal for Engineering, Vol. 2, Issue 6, pp. 115-123

4. Kaushal P., Bux S., Paul, A. (2016). Performances analysis of vortex tube on CFD with straight and helical nozzle. International Journal of Engineering Sciences and Management, Vol. 6, Issue 2, pp. 161-174

5. Kumar N., Malipatil A. S. (2014). CFD Analysis of Vortex Tube for Various Cross-Sectional Nozzles. International Journal for Research in Applied Science \& Engineering Technology, Vol. 2, Issue. X, pp. 291-297

6. Ahmed H., Ahmed M. S., Attalla M., and El-Wafa A. A. (2017). An Experimental Study of Nozzle Number on 
Ranque Hilsch Counter-Flow Vortex Tube. Experimental Thermal and Fluid Science, Vol.82, pp.381-389

7. Bazgir A., Heyderi A. (2018). CFD optimization of injection nozzles geometric dimensions of RHVTmachines in order to enhance the cooling capability. International Journal of Heat and Technology, Vol. 36, Issue 3, pp. 1081-1093

8. Oh Y., Kim K. (2016). A Numerical Study on the Effect of Pitch Angle of Helical Nozzle on the Vortex Tube Performance Characteristics. The KSFM Journal of Fluid Machinery, Vol. 19, Issue 1, pp. 11-17

9. Sadeghiazad M. (2017). Experimental and numerical study on the effect of the convergence angle, injection pressure and injection number on thermal performance of straight vortex tube. International Journal of Heat and Technology, Vol. 35, Issue 3, pp. 651-656

10. Rafiee S., Sadeghiazad M. (2020). Experimental Analysis on Impact of Navigator's Angle on Velocimetry and Thermal Capability of RH-Vortex Tube. Applied Thermal Engineering, Vol., , pp. 1-33.

11. Shamsoddini R., Abolpour B. (2018). A geometric model for a vortex tube based on numerical analysis to reduce the effect of nozzle number. International Journal of Refrigeration, Vol. 94, pp. 49-58

12. Abdelghany S., Kandil H. (2018). Effect of Geometrical Parameters on the Coefficient of Performance of the Ranque-Hilsch Vortex Tube. Open Access Library Journal, Vol. 5, pp. 1-17

13. Suhaimi M., Yusof M. (2018). The Effect of Tube Length and Cold Exit Diameter on The Cold Flow Temperature of Vortex Tube Using High Temperature Working Gas. $1^{s t}$ International Postgraduate Conference on Mechanical Engineering, Malaysia

14. Abd Rahman Kh., Valliyappan W., Natarajan D., Istihat Y. (2017). The Effect of Orifice Diameter to the Acoustic Signal at the Hot Tube of a Ranque-Hilsch Vortex Tube. Journal of Mechanical Engineering, Vol. 2, Issue 1, pp. 29-38

15. Moraveji A., Toghraie D. (2017). Computational fluid dynamics simulation of heat transfer and fluid flow characteristics in a vortex tube by considering the various parameters. International Journal of Heat and Mass Transfer, Vol. 113, pp. 432-443

16. Hamdan M., Al-Omari S., Oweimer A. (2018) Experimental study of vortex tube energy separation under different tube design. Experimental Thermal and Fluid Science, Vol. 91, pp. 306-311

17. Bazgir A., Heyderi A., Nabhani N. (2019). Investigation of the thermal separation in a counter-flow RanqueHilsch vortex tube with regard to different fin geometries located inside the cold tube length. International Communications in Heat and Mass Transfer, Vol. 108 pp. $1-25$

18. Branco F. P., Buchelt E. D., Barbosa F. M., Rosa B. P., Laporte D. J. (2019). Design and study of dimensional parameters influence on vortex tube behavior. Engenharia Térmica, Vol.18, Issue.1, pp. 13-18

19. Zangana L., Barwari R. (2020). The effect of convergentdivergent tube on the cooling capacity of vortex tube: An experimental and numerical study. Alexandric Engineering Journal, Vol.59, Issue.1, pp. 239-246

20. Rafiee S., Sadeghiazad M., Mostafavinia N. (2015) Experimental and Numerical Investigation on Effect of Convergent Angle and Cold Orifice Diameter on Thermal Performance of Convergent Vortex Tube. Journal of Thermal Science and Engineering Applications, Vol.7, pp.1-13

21. Li R., Hu Z., Gao Y. (2019). Numerical Simulation of Energy Separation in a Vortex Tube with Different Vane Number Rectifiers. The 31st Chinese Control and Decision Conference, pp. 5079-5083
22. Rafiee S., Ayenehpour S., Sadeghiazad M. (2016). A study on the optimization of the angle of curvature for a Ranque-Hilsch vortex tube, using both experimental and full Reynolds stress turbulence numerical modelling. Heat Mass Transfer, Vol.52, pp. 337-350

23. Pourmahmoud N., Azar F. S., Hassanzadeh A. (2014). Numerical simulation of secondary vortex chamber effect on the cooling capacity enhancement of vortex tube. Heat Mass Transfer, Vol

24. Skye H.M., Nellis G.F., Klein S.A. (2006). Comparison of CFD analysis to empirical data in a commercial vortex tube. International Journal of Refrigeration, Vol.29, pp. $71-80$

25. Sadi M., Farzaneh-Gord M. (2014). Introduction of Annular Vortex Tube and experimental comparison with Ranque-Hilsch Vortex Tube. International Journal of Refrigeration, Vol.46, pp. 141-151

26. Ismail N., Wisnoe W., M. Remeli (2014). Experimental Investigation of Orifice Diameter, Swirl Generator, and Conical Valve Shape to the Cooling Performance of Ranque-Hilsch Vortex Tube. Applied Mechanics and Materials, Vol. 510, pp. 174-178

27. Abdul Qyyum M., Noon A., Wei F., Le M. (2019). Vortex tube shape optimization for hot control valves through computational fluid dynamics. International Journal of Refrigeration, Vol.102, pp. 151-158

28. Devade K., Pise A. (2016). Exergy analysis of a counter flow Ranque-Hilsch vortex tube for different cold orifice diameters, L/D ratios and exit valve angles. Heat Mass Transfer, Vol.53, Issue 6, pp. 2017-2029

29. Yadav G. M. P., Reddy P. M., Gowd B. U. M. (2016). Effect of end control plugs on the performance of vortex tube with dual forced vortex flow. Journal of Thermal Engineering, Vol.2, Issue.4, pp. 871-881

30. Rafiee S., Sadeghiazad M. (2014). Three-dimensional and experimental investigation on the effect of cone length of throttle valve on thermal performance of a vortex tube using $\mathrm{k}-\mathcal{E}$ turbulence model. Applied Thermal Engineering, Vol. 66, pp. 65-74

\section{Biographical note}

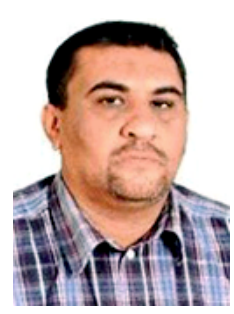

Mustafa Abdulhussain received his M.Sc. degree in as well as his B.Sc. degree in Thermal Power field of Mechanical Engineering from the University of Baghdad, in 1994 and 1997, respectively. Since 2005 he has been a lecturer in the Department of Mechanical Engineering at the University of Technology, where currently he works in the air conditioning and Refrigeration branch. He is one of the teaching staff in the subjects of CAD (Solidworks) and CAE (ANSYS). His scientific research interests focus on CFD simulation in the moving boundary cases and the two-phase flow. He published several scientific papers in international and national journals. 
